\title{
Polymer
}

\section{Pulsed-laser and Quantum Mechanics Study of n-Butyl Cyanoacrylate and Methyl Methacrylate Free-Radical Copolymerization}

\begin{tabular}{|c|c|}
\hline Journal: & Polymer Chemistry \\
\hline Manuscript ID: & PY-ART-10-2014-001423 \\
\hline Article Type: & Paper \\
\hline Date Submitted by the Author: & $18-$ Oct-2014 \\
\hline Complete List of Authors: & $\begin{array}{l}\text { Rooney, Thomas; Queen's University, Chemical Engineering } \\
\text { Mavroudakis, Evangelos; Politecnico di Milano, Chemical Engineering } \\
\text { Lacik, Igor; Polymer Instiute SAS, } \\
\text { Hutchinson, Robin; Queens University, Department of Chemical } \\
\text { Engineering } \\
\text { Moscatelli, Davide; Politecnico di Milano, Chemical Engineering }\end{array}$ \\
\hline
\end{tabular}

\section{SCHOLARONE ${ }^{\text {'w }}$ \\ Manuscripts}




\section{ARTICLE}

Cite this: DOI: 10.1039/xoxxooooox

\section{Pulsed-laser and Quantum Mechanics Study of $\boldsymbol{n}$-Butyl Cyanoacrylate and Methyl Methacrylate Free-Radical Copolymerization}

Received ooth October 2014, Accepted ooth Xxxxxxx 2014

DOI: $10.1039 /$ xoxxooooox

www.rsc.org/

\author{
Thomas R. Rooney, ${ }^{a}$ Evangelos Mavroudakis, ${ }^{\mathrm{b}}$ Igor Lacík, ${ }^{\mathrm{c}}$ Robin A. \\ Hutchinson* ${ }^{* a}$ and Davide Moscatelli*b
}

\section{Introduction}

Alkyl cyanoacrylates (ACAs) are renowned for their extremely rapid anionic polymerization that can be initiated by trace amounts of weak base at room temperature without catalyst. ${ }^{1,2}$ Even moisture from ambient air is sufficient to initiate the fast polymerization and thus ACAs have found widespread applications as 'fast-acting' adhesives. ${ }^{3}$ In addition to remarkable mechanical properties and biocompatibility, poly(alkyl cyanoacrylates) (PACA) demonstrate biodegradability, drug compatibility and permeability that establish them as excellent raw materials for drug delivery systems. $^{4-6}$ Although myriad experimental investigations show PACA nanoparticles (NP) to be promising polymeric colloidal carriers, highly variable in vitro and in vivo results arising from an incomplete control over factors influencing polymerization kinetics, such as competitive initiation by formulation components (i.e. bioactives, excipients, etc.), have been identified as prominent barriers preventing PACA NP drug delivery systems from entering the market. ${ }^{6}$ Indeed, the predominant mechanism for PACA production remains anionic polymerization $^{7-9}$ because of the ease of initiation and the fact that high molecular weights (MW) on the order of
$10^{5}-10^{6} \mathrm{~g} \cdot \mathrm{mol}^{-1}$ can be achieved within seconds. ${ }^{11}$ However, such rapid polymerization is both sensitive and aggressive, necessitating a careful control of operating conditions through the addition of acid stabilizers (e.g., $\mathrm{SO}_{2}$, sulfonic acid, etc). ${ }^{7}$ As a further complication, base catalyzed proton abstraction at the polymer's chain end facilitates a rapid depolymerization mechanism followed by a repolymerization to form new lower MW daughter chains. ${ }^{10,11}$ This depolymerizationrepolymerization behavior makes the anionic polymerization of ACA systems difficult to study, while their remarkably high anionic reactivity limits the choice of suitable monomers for copolymerization. Recently, the possibility to copolymerize ACAs with more stable and common monomers (e.g., methacrylates) by free-radical polymerization (FRP) disclosed new opportunities to control PACA degradation rates. ${ }^{12}$ Although the FRP of alkyl cyanoacrylates is reported to proceed much slower than its anionic polymerization, ${ }^{4}$ the ability to copolymerize through FRP enables a greater control over polymer MW characteristics and degradative behavior while providing a means to tailor polymer properties otherwise inaccessible by anionic polymerization. Furthermore, Robello et al. reported that the copolymerization of ethyl cyanoacrylate (ECA) with only $5 \mathrm{wt} \%$ methyl methacrylate (MMA) is 
sufficient to halt the depolymerization of the poly(ECA) backbone in basic medium. ${ }^{10}$

Investigations on the FRP kinetics of ACAs are scarce in the literature, and to the best of the authors' knowledge there is no experimental work to estimate individual free-radical propagation rate coefficients for ACA copolymerization systems. However, using the rotating sector method Yamada et al. estimated the homo-propagation rate coefficient $\left(k_{\mathrm{p}}\right)$ of ECA in bulk at $30{ }^{\circ} \mathrm{C}$ to be $1622 \mathrm{~L} \cdot \mathrm{mol}^{-1} \cdot \mathrm{s}^{-1}$, approximately 3.6 times their estimate of $k_{\mathrm{p}}$ for MMA. ${ }^{13}$ Furthermore, Yamada et al. found that the cyano group $(-\mathrm{CN})$ at the $\alpha$ - position has a similar influence on propagation kinetics as the $\alpha$-chloro substituent ${ }^{14}$ and a $45 \%$ increase in $k_{\mathrm{p}}$ compared to the $\alpha$-fluoro substituent, ${ }^{15}$ with a recent computational study performed by Değirmenci et al. supporting these experimental findings. ${ }^{16}$

In this work, the pulsed-laser polymerization coupled with size exclusion chromatography (PLP-SEC) technique is used to study the free-radical polymerization kinetics of the $n$-butyl cyanoacrylate (BCA) and MMA copolymerization system. MMA is selected as comonomer because of its biocompatibility, ${ }^{17}$ confirmed ability to halt depolymerization of PACA backbone, ${ }^{10}$ and well-documented FRP kinetics. ${ }^{18}$ The PLP-SEC technique is recommended by the IUPAC subcommittee on modeling of polymerization kinetics and processes as the most accurate and reliable method to critically evaluate propagation rate coefficients, and is described in comprehensive detail by Beuermann and Buback. ${ }^{19}$ The copolymer composition-averaged propagation rate coefficient $\left(k_{\mathrm{p}, \text { cop }}\right)$ can be calculated using Equation (1) where $\mathrm{MW}_{\mathrm{i}}$ is the molecular weight corresponding to the $i$ th inflection point of the low-conversion PLP-generated molecular weight distribution (MWD) as measured by size exclusion chromatography (SEC), $\rho_{\text {mon }}$ is the density of the monomer mixture calculated assuming volume additivity, $\phi_{\text {mon }}$ is the volume fraction of monomer, and $t_{0}$ is the time between pulses:

$$
k_{\mathrm{p}, \mathrm{cop}}=\frac{M W_{\mathrm{i}}}{i \cdot \emptyset_{\text {mon }} \cdot 1000 \cdot \rho_{\mathrm{mon}} \cdot t_{\mathrm{o}}} ; \quad i=1,2,3 \ldots
$$

PLP-SEC has been used to establish benchmark $k_{\mathrm{p}}$ values over a wide range of temperatures for $\mathrm{MMA}^{18}$ as well as $n$-butyl methacrylate (BMA) ${ }^{20}$ and butyl acrylate (BA), ${ }^{21}$ monomers which are structurally similar to BCA yet different in $\alpha$ substituent. Furthermore, low-conversion PLP-generated copolymers can be analyzed by ${ }^{1} \mathrm{H}-\mathrm{NMR}$ to determine copolymer composition in order to estimate reactivity ratios for the system that describe the copolymer sequence distribution along the backbone.

Monomer-family trends are well-documented for reactivity ratios, where methacrylate/methacrylate copolymerization systems polymerize randomly, and acrylate/methacrylate systems tend towards methacrylate rich copolymers. ${ }^{22}$ However, the current understanding of alkyl cyanoacrylate reactivity is incomplete, as summarized in Table 1.

For bulk methacrylate/cyanoacrylate systems Kinsinger et al. report a random sequence (and strongly alternating in benzene), while the work of Yamada et al. claims a strongly
Table 1 Reactivity ratio estimates for ACA/MMA systems available in the literature.

\begin{tabular}{cccccc}
\hline ACA alkyl type & Medium & $\begin{array}{c}\text { Temperature } \\
\left({ }^{\circ} \mathrm{C}\right)\end{array}$ & $r_{\text {ACA }}$ & $r_{\text {MMA }}$ & Ref. \\
\hline ethyl & Bulk & 60 & 0.85 & 0.41 & 12 \\
ethyl & Bulk & 30 & 0.16 & 0.08 & 13 \\
methyl & Benzene & 60 & 0.25 & 0.04 & 23 \\
\hline
\end{tabular}

alternating sequence for bulk polymerization..$^{13,23}$ In addition, the high-conversion experiments of Han and Kim indicate that the bulk copolymerization of ECA/MMA tends towards a random system. ${ }^{12}$ In all of these works the authors emphasize the difficulty in suppressing anionic polymerization during FRP and isolation of the low-conversion copolymer. The current experimental study was undertaken to resolve these inconsistencies seen in previous literature, and to provide a detailed understanding of BCA FRP kinetics from which PACAs may be synthesized with highly reproducible final properties. In addition, a computational approach based on density functional theory (DFT) is applied to support and enrich the BCA/MMA copolymerization experiments. The terminal model (TM) of copolymerization kinetics ${ }^{24}$ is assumed for the computational investigation of the copolymer system, with rate coefficients for the involved propagation reactions and copolymer composition as a function of monomer mole fraction estimated at $50{ }^{\circ} \mathrm{C}$.

\section{Experimental}

Methyl methacrylate (MMA, 99\%, Sigma Aldrich), n-butyl cyanoacrylate (BCA, Henkel Biomedical, Dublin, Ireland), 2,2dimethoxy-2-phenylacetophenone (DMPA, 99\%, Sigma Aldrich), dichloroacetic acid (DCAA, $\geq 99 \%$, Sigma Aldrich), methacrylic acid (MAA, $99 \%$, Sigma Aldrich), chloroform-d $\left(\mathrm{CDCl}_{3}, 99.8 \% \mathrm{D}\right.$, Cambridge Isotope Laboratories), methanol ( $\mathrm{MeOH}$, reagent grade, ACP Chemicals Inc.), and acetone (reagent grade, ACP Chemicals Inc.) were all used as received. Low-conversion copolymerizations of $\mathrm{BCA} / \mathrm{MMA}$ were conducted at Queen's University using a pulsed laser setup consisting of a Coherent Xantos XS-500 laser operating at the XeF line of $351 \mathrm{~nm}$ and capable of producing laser energy of 1$60 \mathrm{~mJ}$ per pulse at repetition rates up to $500 \mathrm{~Hz}$, while a similar setup was also used at the Polymer Institute of the Slovak Academy of Sciences (Polymer Institute SAS). ${ }^{25}$ Monomer mixtures of various BCA/MMA composition were prepared in bulk with $1 \mathrm{v} \%$ DCAA and $5 \mathrm{mmol} \cdot \mathrm{L}^{-1}$ DMPA photoinitiator. Approximately $1 \mathrm{~mL}$ of the monomer mixture was added to a Quartz cuvette of $10 \mathrm{~mm}$ pathlength (CV10Q3500S, Thorlabs), heated to $50{ }^{\circ} \mathrm{C}$ using a circulating oil bath, and exposed to laser energy while the temperature was monitored and controlled to within $50 \pm 1{ }^{\circ} \mathrm{C}$. In addition, several experiments were also carried out at $30 \pm 1{ }^{\circ} \mathrm{C}$ and $70 \pm 1{ }^{\circ} \mathrm{C}$. Experiments were conducted using laser repetition rates between 10 and 100 $\mathrm{Hz}$ (see Table S4 of the Supporting Information for the exact operating conditions employed for each sample). 
Table 2 Parameters for interpretation of SEC results and calculation of $k_{\mathrm{p}, \mathrm{cop}}$.

\begin{tabular}{|c|c|c|c|c|c|}
\hline \multirow[b]{2}{*}{ Monomer } & \multirow[b]{2}{*}{$\rho\left(\mathrm{g} \cdot \mathrm{mL}^{-1}\right)$} & \multirow[b]{2}{*}{$\begin{array}{c}d n / d c \\
\left(\mathrm{~mL} \cdot \mathrm{g}^{-1}\right)\end{array}$} & \multicolumn{3}{|c|}{ Mark-Houwink parameters } \\
\hline & & & $\begin{array}{c}K\left(\mathrm{dL} \cdot \mathrm{g}^{-1}\right) \times \\
10^{-4}\end{array}$ & $a$ & Ref \\
\hline Styrene & N/a & 0.185 & 1.14 & 0.716 & 26 \\
\hline MMA & $\begin{array}{c}0.9671- \\
0.001117 \mathrm{~T} /{ }^{\circ} \mathrm{C}^{\mathrm{a}}\end{array}$ & $0.089^{27}$ & 0.944 & 0.719 & 28 \\
\hline BCA & $\begin{array}{c}1.0140- \\
0.009326 \mathrm{~T} /{ }^{\circ} \mathrm{C}^{\mathrm{a}}\end{array}$ & $0.074^{\mathrm{a}}$ & 2.00 & 0.571 & 29 \\
\hline
\end{tabular}

To minimize compositional drift, the monomer conversion for each experiment was kept below $3 \%$ as measured by gravimetry. Following PLP experiments, the residual MMA monomer was removed under constant air stream. The resulting copolymer/BCA monomer mixture was treated with 7-25 mL of methanol $(\mathrm{MeOH})$ containing $5 \mathrm{v} \%$ MAA at room temperature, centrifuged at $6000 \mathrm{rpm}$ for 10 minutes, with the supernatant then decanted to collect the copolymer precipitate. To remove any remaining BCA monomer the same procedure was repeated. The final step to remove all acidic species was to redissolve the copolymer in a minimum amount of acetone and then re-precipitate with non-acidified $\mathrm{MeOH}$, centrifuge, and isolate the copolymer product.

The molecular weights of all copolymer samples produced at Queen's University were determined by SEC using the Waters 2960 separation module instrument with distilled tetrahydrofuran (THF) as eluent. Two detectors were connected to the instrument: a Waters 410 differential refractometer (RI) and a Wyatt Instrument Dawn EOF light scattering detector (LS). The flow rate of THF was programmed to $0.3 \mathrm{~mL} / \mathrm{min}$ and the sample was passed through four Styragel columns (HR $0.5,1,3,4)$ maintained at $35{ }^{\circ} \mathrm{C}$. The SEC analysis of the samples produced at the Polymer Institute SAS was also performed with THF as eluent using a setup described elsewhere. $^{25}$ In both setups, the RI detector was calibrated using polystyrene standards, while both RI and LS output were interpreted using the literature and measured calibration parameters listed in Table 2. The copolymer MW was calculated as a composition-weighted average of the homopolymer values using literature $\mathrm{MH}$ parameters, while a composition-weighted $d n / d c$ value was used to interpret the LS output. The $d n / d c$ value for PBCA was measured using a Wyatt Optilab DSP refractometer at $690 \mathrm{~nm}$ calibrated with sodium chloride. Six PBCA samples of $1-20 \mathrm{mg} \cdot \mathrm{mL}^{-1}$ were prepared in distilled THF and injected sequentially to construct the curve with slope $d n / d c$. Finally, the monomer densities were measured at temperatures between 20 and $70{ }^{\circ} \mathrm{C}$ using a Paar DMA 48 Density Meter, with best-fit parameters reported in Table 2 .

\section{Computational Details}

The TM is the most frequently employed model to characterize copolymer systems because its ability to describe FRP processes has been critically tested and verified. ${ }^{30}$ This model assumes that the reactivity of the propagating radical depends only on the identities of the radical and monomer to be added. Accordingly, a simple scheme composed by four reactions (Scheme 1) is sufficient to describe a copolymer system.

$$
\begin{aligned}
& \sim \sim \sim \mathrm{A}^{\cdot}+\mathrm{A} \stackrel{k_{\mathrm{AA}}}{\rightarrow \sim \sim \sim \mathrm{AA}^{\circ}} \\
& \sim \sim \mathrm{A}^{\cdot}+\mathrm{B} \stackrel{k_{\mathrm{AB}}}{\rightarrow \sim \sim \sim \mathrm{AB}^{\circ}} \\
& \sim \sim \sim \mathrm{B}^{\circ}+\mathrm{A} \stackrel{k_{\mathrm{BA}}}{\rightarrow \sim \sim \sim \mathrm{BA}^{\circ}} \\
& \sim \sim \sim \mathrm{B}^{*}+\mathrm{B} \stackrel{k_{\mathrm{BB}}}{\rightarrow \sim \sim \sim \mathrm{BB}^{\circ}}
\end{aligned}
$$

Scheme 1 Elementary propagation reactions of a binary copolymer system according to the terminal model.

It follows that the monomer reactivity ratios $r_{\mathrm{A}}$ and $r_{\mathrm{B}}$ can be calculated using the estimated values for the kinetic coefficients as defined by Equations (2) and (3), respectively, while the mole fraction of repeat unit $\mathrm{A}$ in the copolymer $\left(F_{\mathrm{A}}\right)$ is represented by Equation (4) as a function of initial monomer mole fractions $\left(f_{\mathrm{A}}\right.$ and $\left.f_{\mathrm{B}}\right)$ and monomer reactivity ratios. ${ }^{24}$ Finally, Equation (5) gives the expression for the overall copolymer propagation rate coefficient derived by the TM.

$$
\begin{aligned}
& r_{\mathrm{A}}=\frac{k_{\mathrm{AA}}}{k_{\mathrm{AB}}} \\
& r_{\mathrm{B}}=\frac{k_{\mathrm{BB}}}{k_{\mathrm{BA}}} \\
& F_{\mathrm{A}}=\frac{r_{\mathrm{A}} f_{\mathrm{A}}^{2}+f_{\mathrm{A}} f_{\mathrm{B}}}{r_{\mathrm{A}} f_{\mathrm{A}}^{2}+2 f_{\mathrm{A}} f_{\mathrm{B}}+r_{\mathrm{B}} f_{\mathrm{B}}^{2}} \\
& k_{\mathrm{p}, \mathrm{cop}}=\frac{r_{\mathrm{A}} f_{\mathrm{A}}^{2}+2 f_{\mathrm{A}} f_{\mathrm{B}}+r_{\mathrm{B}} f_{\mathrm{B}}^{2}}{\left(r_{\mathrm{A}} \frac{f_{\mathrm{A}}}{k_{\mathrm{AA}}}\right)+\left(r_{\mathrm{B}} \frac{f_{\mathrm{B}}}{k_{\mathrm{BB}}}\right)}
\end{aligned}
$$

From Equations (2-5), it is clear that knowledge of the rate coefficients for each of the propagation reactions in Scheme 1 is required to estimate the overall kinetic coefficient as well as the copolymer composition as a function of initial comonomer composition. Transition state theory (TST) provides a simple and useful way to determine the rate coefficients of chemical reactions, and was therefore used to determine all required values for each propagation reaction in the BCA/MMA copolymerization system. 
Table 3 Arrhenius kinetic parameters for each monomer to radical addition in the $\mathrm{BCA} / \mathrm{MMA}$ copolymerization system as well as reactivity ratios at $50{ }^{\circ} \mathrm{C}$

\begin{tabular}{|c|c|c|c|}
\hline & $\begin{array}{c}E_{\mathrm{a}} \\
\left(\mathrm{kJ} \cdot \mathrm{mol}^{-1}\right)\end{array}$ & $\log _{10}(A)$ & $\begin{array}{c}k_{\mathrm{ij}} \\
\left(\mathrm{L} \cdot \mathrm{mol}^{-1} \cdot \mathrm{s}^{-1}\right)\end{array}$ \\
\hline $\mathrm{BCA}^{\circ}+\mathrm{BCA}^{\circ}$ & 17.52 & 3.95 & 12.9 \\
\hline $\begin{array}{l}\mathrm{BCA}^{\cdot}+\mathrm{MMA} \\
\mathrm{MMA}^{\cdot}+\mathrm{BCA}\end{array}$ & $\begin{array}{c}15.59 \\
0.63\end{array}$ & $\begin{array}{l}4.17 \\
3.92\end{array}$ & $\begin{array}{l}47.4 \\
6640\end{array}$ \\
\hline $\mathrm{MMA}^{\cdot}+\mathrm{MMA}^{\prime}$ & 11.14 & 4.38 & 381 \\
\hline \multicolumn{4}{|c|}{ Monomer reactivity ratios } \\
\hline$r_{\mathrm{BCA}}$ & \multicolumn{3}{|c|}{0.272} \\
\hline$r_{\mathrm{MMA}}$ & \multicolumn{3}{|c|}{0.057} \\
\hline
\end{tabular}

${ }^{a}$ Rate coefficients were calculated at $50^{\circ} \mathrm{C}$. BCA $:$ BCA radical; MMA ${ }^{\circ}$ : MMA radical; BCA: BCA monomer; MMA: MMA monomer; $\left(k_{\mathrm{ij}} i, j=\mathrm{BCA}\right.$, MMA). The data represent the Arrhenius parameters determined using the combined B3LYP/6-31(d,p)//MPWB1K/6-31(d,p) approach.

Under certain assumptions, TST proposes the following expression for the thermal rate coefficient of a bimolecular reaction:

$$
k(T)=\frac{k_{\mathrm{b}} T}{h} \frac{Q^{\neq}}{Q_{\mathrm{A}} Q_{\mathrm{B}}} \mathrm{e}^{-\frac{E_{\mathrm{a}}}{k_{\mathrm{b}} T}}
$$

where $k_{\mathrm{b}}$ and $h$ are the Boltzmann and Planck constants, respectively, $T$ is the temperature, $E_{\mathrm{a}}$ is the activation energy of the process, $Q_{\mathrm{A}}$ and $Q_{\mathrm{B}}$ are the partition functions for the reactants, and $Q^{\neq}$is the partition function of the transition state. A standard expression for the total partition function $(Q)$ associated with the internal motion for each molecule is given by Equation (7) as the product of the rotational, vibrational, electronic, and translational partition functions.

$$
Q=Q_{\text {rot }} Q_{\text {vib }} Q_{\text {elec }} Q_{\text {trans }}
$$

The kinetic parameters required to assess the partition function as well as the electronic $\left(E_{\mathrm{e}}\right)$ and the zero-point $\left(E_{\mathrm{zp}}\right)$ energies that are needed to evaluate activation energy can be estimated through Quantum Chemistry. More specifically, the activation energy of a reaction is defined as the difference between the sums of the electronic and zero-point energies for the transition state and the reactants, as shown in Equation (8).

$$
E_{\mathrm{a}}=\left(E_{\mathrm{e}}+E_{\mathrm{ZP}}\right)_{\neq}-\prod_{i}^{N_{\mathrm{r}}}\left(E_{\mathrm{e}}+E_{\mathrm{ZP}}\right)_{i}
$$

The procedure described hereinafter was followed to obtain the reaction rate coefficients using Quantum Mechanics (QM).

Firstly, the hybrid DFT method B3LYP, which is a combination of the Becke 3 parameters exchange functional ${ }^{31}$ and the Lee-Tang-Parr correlation functional, ${ }^{32}$ was used for the geometry optimization of the molecules (reactants and products) as well as the detection and the optimization of the transition state geometry. The Pople basis set $6-31 \mathrm{G}$, with the addition of the polarization and diffuse functions, was used to describe the molecular orbitals. A large number of potential energy surfaces (PES) for the rotation of various dihedral angles were used to detect the optimized geometries for reactants and products, whereas the transition state geometries were detected using the PES obtained after a discrete scan of the bond formation distance along the reaction coordinate. After the detected geometries were optimized at the B3LYP/6$31 \mathrm{G}(\mathrm{p}, \mathrm{d})$ level of theory, the obtained structures were used for single point calculations using a higher level of theory provided by the hybrid meta DFT method MPWB1K ${ }^{33}$ The single point simulations at the MPWB $1 \mathrm{~K} / 6-31 \mathrm{G}(\mathrm{p}, \mathrm{d})$ level of theory provide more accurate estimations of the electronic and zero point energies. The suitability of the B3LYP/6$31 \mathrm{G}(\mathrm{p}, \mathrm{d}) / / \mathrm{MPWB} 1 \mathrm{~K} / 6-31 \mathrm{G}(\mathrm{d}, \mathrm{p})$ approach has been proven for the study of propagation and secondary reactions of various polymer systems. ${ }^{34-40}$ All of the thermodynamic and kinetic data in this work were estimated using the Gaussian 09 program suite. $^{41}$

In the present study, the rate coefficients associated with the propagation reactions illustrated in Scheme 1 were estimated for the BCA/MMA copolymerization system following the procedure described above. The obtained computational results for the rate coefficients along with the monomer reactivity ratios are presented in Table 3, with results compared to experiment in the Results and Discussion section below.

\section{Results and Discussion}

\section{BCA/MMA Copolymer Composition Analysis}

Low-conversion free-radical generated copolymer compositions estimates are difficult to obtain for ACA systems because of the extremely rapid anionic polymerization of the monomer. Previous authors have attempted to mitigate this issue by precipitating their desired polymer from solution using methanol $(\mathrm{MeOH})$ containing $5 \mathrm{wt} \%$ hydrochloric acid $(\mathrm{HCl}) .{ }^{12,29}$ Although $\mathrm{MeOH}$ itself is a nucleophile the presence of $\mathrm{HCl}$ is designed to quickly cap any anionic species formed. In this work, $\mathrm{MeOH}$ acidified with $5 \mathrm{wt} \% \mathrm{HCl}$ was unsuitable to isolate low-conversion PLP-generated FRP copolymers, as subtle changes in $\mathrm{HCl}$ solubility in $\mathrm{MeOH}$ with temperature and during centrifugation inevitably led to the formation of anionic PBCA during isolation. Instead, $\mathrm{MeOH}$ containing $5 \mathrm{v} \%$ methacrylic acid (MAA) was used to effectively precipitate 


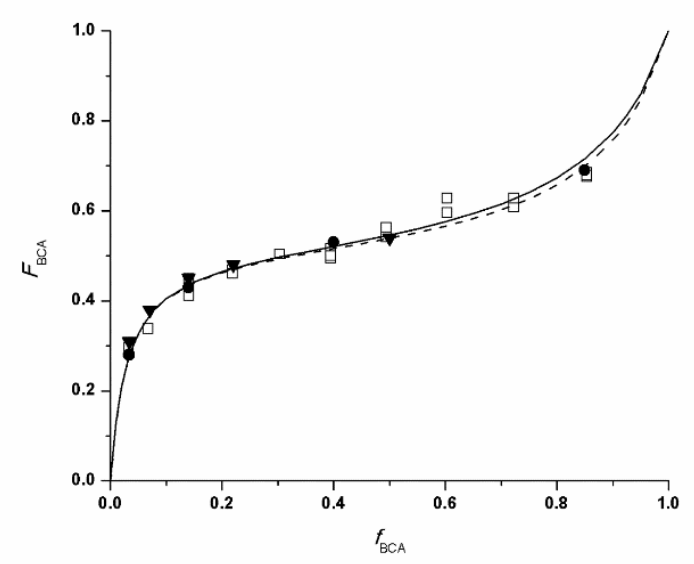

Figure 1 BCA/MMA copolymer composition vs. initial molar fraction of BCA polymerized in bulk at $30^{\circ} \mathrm{C}(\boldsymbol{\nabla}), 50{ }^{\circ} \mathrm{C}(\square)$, and $70{ }^{\circ} \mathrm{C}(\bullet)$ with $1 \mathrm{v} \%$ DCAA to suppress anionic polymerization. Experimental data at $50{ }^{\circ} \mathrm{C}$ fitted by the terminal model with $r_{\mathrm{BCA}}=0.236 \pm 0.042$ and $r_{\mathrm{MMA}}=0.057 \pm 0.008$ (dashed line), while the solid line indicates terminal model predictions with $r_{\mathrm{BCA}}=0.272$ and $r_{\mathrm{MMA}}=$ 0.057 estimated computationally.

low conversion FRP-generated copolymer from residual monomer at room temperature. When MAA, whose density is similar to that of BCA, is used as the acidic end-capping agent the residual monomer is not segregated during centrifugation and therefore the formation of anionic PBCA is prevented altogether. As outlined in the Supporting Information, the ${ }^{1} \mathrm{H}$ NMR spectra of the isolated FRP copolymer (Figure S1) provided three independent estimates of copolymer composition for which the presence of any anionicallygenerated PBCA homopolymer leads to a distinct disagreement. Copolymer composition results were only deemed as reliable (i.e., not contaminated by PBCA homopolymer formed during sample workup) if the three independent calculations of copolymer composition were within $3 \%$ of each other (Table S1). As a further validation of the effectiveness of this copolymer isolation technique, several samples were produced at different repetition rates for each initial monomer composition and the corresponding copolymer compositions were estimated with excellent reproducibility. The final results are presented in Figure 1, where the $50{ }^{\circ} \mathrm{C}$ data is fitted according to the terminal model with reactivity ratios estimated by non-linear parameter estimation. There is excellent agreement at the $95 \%$ confidence level between the values $\left(r_{\mathrm{BCA}}=0.236 \pm 0.042\right.$ and $\left.r_{\mathrm{MMA}}=0.057 \pm 0.008\right)$ fitted to experimental data with the values $\left(r_{\mathrm{BCA}}=0.272\right.$ and $r_{\mathrm{MMA}}=$ $0.057)$ predicted by Quantum Mechanics. Included in Figure 1 are copolymer compositions for samples produced at 30 and 70 ${ }^{\circ} \mathrm{C}$; as the data are in excellent agreement with both sets of reactivity ratio estimates at $50{ }^{\circ} \mathrm{C}$, it can be concluded that there is no significant variation in bulk BCA/MMA reactivity ratios over the $30-70{ }^{\circ} \mathrm{C}$ temperature range.

Copolymer composition estimates beyond $f_{\mathrm{BCA}}=0.85$ were not reliable, as the copolymer could not be successfully isolated from the residual monomer without inducing anionic polymerization. This difficulty introduces higher uncertainty in the estimate of $r_{\mathrm{BCA}}$ from experimental data. Nevertheless, the amount and reproducibility of the data presented in Figure 1 is sufficient to show that the BCA/MMA copolymerization system is well-represented by the terminal model, and demonstrates its strongly alternating character, in agreement with the findings of Yamada et al. in bulk ${ }^{13}$ and Kinsinger et al. in benzene ${ }^{23}$ (see Table 1). The direct low-conversion estimates in this work confirm a strongly alternating system which facilitates BCA incorporation while minimizing the mutual repulsion between dipolar $-\mathrm{CN}$ groups. This is supported by QM calculations which indicate that the BCA dimer radical structure which possesses the minimum energy is syndiotactic (Figure S5) as well as the work of Markova et al. in which it is reported that the anionic polymerization of BCA also adopts a syndiotactic conformation to minimize the repulsion between adjacent dipolar $-\mathrm{CN}$ groups. ${ }^{42}$ Furthermore, the reproducibility of the low-conversion data in Figure 1 confirms that the incorporation of MMA through FRP successfully halts the wellknown depolymerization-repolymerization behavior of PACAs over a wide range of initial monomer compositions. Although Robello et al. reported that an initial composition containing only $5 \mathrm{wt} \%$ MMA $\left(f_{\mathrm{BCA}}=0.93\right)$ is enough to halt depolymerization of the PACA backbone in basic medium, ${ }^{10}$ the number of incorporated MMA units corresponding to $f_{\mathrm{BCA}}=0.93$ could not be confirmed by experimentation. However, the reactivity ratio estimates used to fit the data in Figure 1 indicate that depolymerization is halted when at least 2 of every 10 units in a copolymer sequence are MMA (i.e. $f_{\mathrm{BCA}}=0.93$ yields copolymer of composition $F_{\mathrm{BCA}}=0.8$ ).

\section{BCA/MMA composition-averaged copolymer propagation rate coefficient estimation}

Pulsed-laser polymerization experiments were performed for various mixtures of $\mathrm{BCA} / \mathrm{MMA}$ in bulk at $50{ }^{\circ} \mathrm{C}$ and repetition rates ranging from $10-100 \mathrm{~Hz}$. In this work, BCA/MMA samples are pulsed in the presence of $1 \mathrm{v} \%$ DCAA to suppress the anionic polymerization of BCA. Robello et al. showed that DCAA can effectively inhibit ACA anionic polymerization in solution, ${ }^{10}$ and the validation of the copolymer composition results in Figure 1 confirms that $1 \mathrm{v} \%$ DCAA is sufficient to suppress BCA anionic polymerization under bulk FRP conditions at 30,50 , and $70{ }^{\circ} \mathrm{C}$. As described in the Supporting Information (Figure S2 and Table S2), the estimation of $k_{\mathrm{p}}$ from PLP-SEC analysis of bulk MMA homopolymerization is not affected when $1 \mathrm{v} \%$ DCAA is added to the reaction mixture, and there is also no significant change in $k_{\mathrm{p} \text {,cop }}$ estimation when the content of DCAA is systematically varied from 0.1 to 3.0 $\mathrm{v} \%$. Supporting the conclusion that the addition of acid does not affect the estimation of $k_{\mathrm{p}}$, Yamada et al. found no effect of acid type in the study of ECA bulk free-radical homopolymerization at $30{ }^{\circ} \mathrm{C}$ using the rotating sector method, with two different acids employed to suppress anionic polymerization. ${ }^{13}$ Given the above observations it can be safely concluded that the addition of $1 \mathrm{v} \%$ DCAA does not influence 
the free-radical copolymerization propagation kinetics over the range of reaction conditions studied in this work.

As previously outlined, a major challenge associated with applying the PLP-SEC technique to the BCA/MMA system is to isolate the low-conversion FRP-generated copolymer without inducing anionic polymerization of residual BCA monomer. If reduced temperature or $\mathrm{MeOH}$ containing $5 \mathrm{wt} \% \mathrm{HCl}$ are employed to precipitate the PLP samples from residual monomer the resulting MWD and $1^{\text {st }}$ derivative plots will resemble those shown in Figure 2, where Blank corresponds to the polymer formed (presumably by anionic polymerization of BCA) during work-up of a comonomer mixture which was not exposed to laser energy but was still treated with $\mathrm{MeOH}$ containing $5 \mathrm{wt} \% \mathrm{HCl}$. Note the presence of the inflection point near $\log (M W)=4.7$ on the high-MW side of the distribution in each sample, regardless of PLP reaction temperature. This peak must be a result of the anionic polymerization of BCA during the isolation procedure, for if it had been produced during the PLP experiment a shift in MW corresponding to reaction temperature would be expected. The PLP distributions are found at lower MW than the contaminant peak and the primary inflection points increase with reaction temperature, as

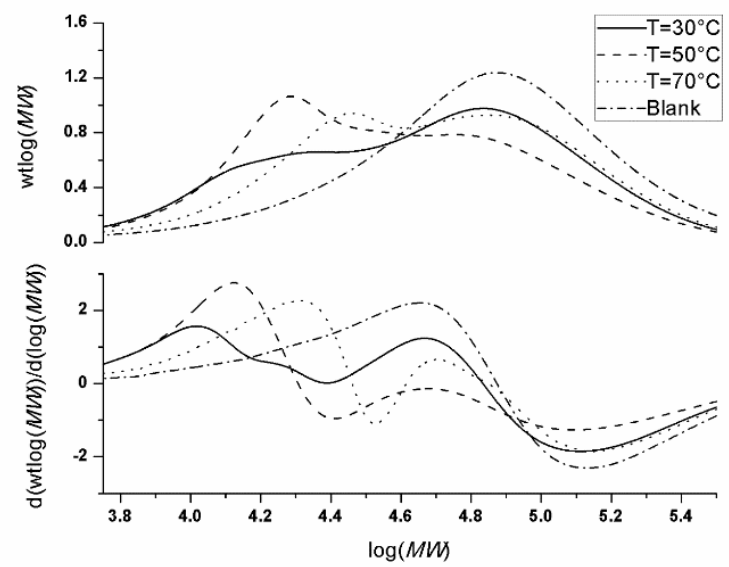

Figure 2 MWDs and 1st derivative plots from RI output when reduced temperature or $\mathrm{MeOH}$ containing $5 \mathrm{wt} \% \mathrm{HCl}$ is employed to precipitate PLP samples generated from $f_{\mathrm{BCA}}=0.22$ and $100 \mathrm{~Hz}$ at various temperatures. Blank corresponds to a PLP sample which underwent identical treatment except it was not exposed to laser energy.


Figure 3 MWDs and 1st derivative plots from RI and LS detectors for BCA/MMA bulk PLP experiments at $50{ }^{\circ} \mathrm{C}$ and $50 \mathrm{~Hz}$ with $1 \mathrm{v} \%$ DCAA and 5 mmol $\mathrm{L}^{-1} \mathrm{DMPA}$ photoinitiator. PLP polymer isolation was performed with $\mathrm{MeOH}$ containing 5 v\% MAA at room temperature. 
expected. However, the secondary inflection points expected from the PLP experiment are obscured by the contaminant PBCA peak, preventing the accurate determination of $k_{\mathrm{p}, \text { cop }}$ by negatively affecting the PLP consistency checks. ${ }^{19,20}$ When $\mathrm{MeOH}$ containing $5 \mathrm{v} \% \mathrm{MAA}$ is employed at room temperature the issue of contaminant PBCA is averted to yield typical MWDs and $1^{\text {st }}$ derivative plots like those presented in Figure 3.

The MWDs and $1^{\text {st }}$ derivative plots in Figure 3 indicate that the polymer was produced and isolated without significant amounts of contaminant PBCA and show good PLP structure from both RI and LS detectors. Furthermore, when all acidic species are removed, by re-dissolving the isolated PLP samples in a minimum amount of acetone and re-precipitating in $\mathrm{MeOH}$, a good agreement is achieved between the RI and LS estimates for $k_{\mathrm{p} \text {,cop }}$ over the entire composition range. The differences between detectors do not exceed $15 \%$ which justifies the composition-weighted approaches to interpreting RI and LS data as well as the measurement of the $d n / d c$ and the usage of literature Mark-Houwink parameters for PBCA. ${ }^{29}$ PLP samples produced from $\mathrm{BCA}$ compositions greater than $f_{\mathrm{BCA}}=0.85$ could not be isolated from residual monomer without exposing them to a lower temperature $\left(-10{ }^{\circ} \mathrm{C}\right)$ or treating them with $\mathrm{MeOH}$ containing less than $5 \mathrm{v} \%$ MAA. This compromise inevitably led to the appearance of contaminant PBCA in the GPC traces, and therefore reliable $k_{\mathrm{p} \text {,cop }}$ estimation could not be made for samples produced from BCA compositions greater than $f_{\mathrm{BCA}}=0.85$.

Individual $k_{\mathrm{p} \text {,cop }}$ estimates were deemed reliable only if the ratio of secondary to primary inflection point $\left(\mathrm{M}_{2} / \mathrm{M}_{1}\right)$ was contained within the interval of $1.8-2.2$ and if there was consistency between estimates made from the same composition yet different repetition rates (see Table S4 of the Supporting Information). In general, repetition rates of 33 and $50 \mathrm{~Hz}$ led to MWDs with the best PLP structures, but for higher BCA content systems lower repetition rates were favorable. This observation is likely related to the fact that lower repetition rates generate higher MW copolymer which facilitates an easier precipitation of the copolymer from residual monomer. Estimations for the $k_{\mathrm{p} \text {,cop }}$ at $f_{\mathrm{BCA}}=0.93$ could be inferred from the primary inflection point location amongst samples pulsed at different repetition rates, but lack of suitable $\mathrm{M}_{2} / \mathrm{M}_{1}$ for any of the samples makes them unreliable (see Table S3 and Figure S3 of the Supporting Information). As shown in Figure S4 of the Supporting Information, no discernible PLP structure could be obtained from the bulk homopolymerization of BCA at 50 or $75^{\circ} \mathrm{C}$ due to the rapid depolymerization of the PBCA backbone while awaiting injection into the THF-based SEC instrument.

Reliable $k_{\mathrm{p} \text {,cop }}$ estimates from the SEC RI analysis of PLPgenerated polymer produced by BCA/MMA bulk polymerizations at $50{ }^{\circ} \mathrm{C}$ are presented in Figure 4 as a function of comonomer composition. The excellent agreement between experiments performed in the laboratories of Queen's University and the Polymer Institute SAS further strengthens the reliability of the $k_{\mathrm{p} \text {,cop }}$ data set for this experimentally

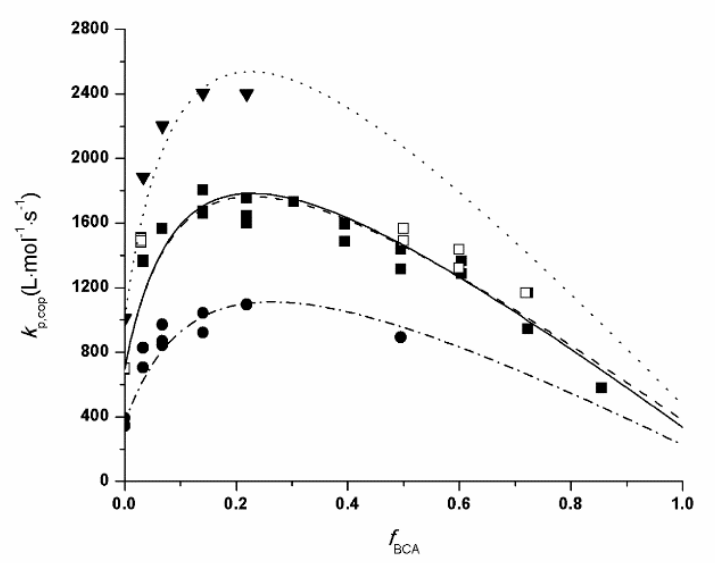

Figure $4 k_{\text {p,cop }}$ experimental estimations using RI detector output for bulk BCA/MMA copolymerizations with $1 \mathrm{v} \%$ DCAA and $5 \mathrm{mmol}^{-1} \mathrm{~L}^{-1}$ DMPA. Experiments performed at $50{ }^{\circ} \mathrm{C}$ at Queen's University (घ) and the Polymer Institute SAS ( $\square$ ) are fitted to the terminal model using reactivity ratios from Quantum Mechanics (solid line) of $r_{\mathrm{BCA}}=0.272$ and $r_{\mathrm{MMA}}=0.057$ as well as from experimental (dashed line) of $r_{\mathrm{BCA}}=0.236$ and $r_{\mathrm{MMA}}=0.057$. Experimental reactivity ratios are also used for terminal model fits to $k_{\mathrm{p}, \mathrm{cop}}$ estimates made at 70 ${ }^{\circ} \mathrm{C}(\boldsymbol{\nabla}$, dotted line $)$ and $30{ }^{\circ} \mathrm{C}(\bullet$, dash-dotted line $)$.

challenging polymerization system. However, since a value of $k_{\mathrm{p}, \mathrm{BCA}}$ could not be obtained experimentally, it was estimated by fitting the $k_{\mathrm{p} \text {,cop }}$ data to the terminal model with $k_{\mathrm{p}, \mathrm{BCA}}$ the only unknown parameter. The non-linear parameter estimation was done twice, using the two sets of reactivity ratios determined in Figure 1 as well as an average of the $k_{\mathrm{p}, \mathrm{MMA}}$ values measured in this work.

The shape of the $k_{\mathrm{p}, \text { cop }}$ data is well-represented by both fits at the $95 \%$ confidence level, with the corresponding estimates for bulk $k_{\mathrm{p}, \mathrm{BCA}}$ at $50{ }^{\circ} \mathrm{C}$ of $379 \pm 32 \mathrm{~L} \cdot \mathrm{mol}^{-1} \cdot \mathrm{s}^{-1}$ and $336 \pm 20$ $\mathrm{L} \cdot \mathrm{mol}^{-1} \cdot \mathrm{s}^{-1}$, when using Quantum Mechanics and experimentally-fit reactivity ratios, respectively. It is worth mentioning that as described in the literature, ${ }^{43-44} \mathrm{QM}$ calculations are more accurate for the prediction of relative rate coefficients than the prediction of absolute values. Therefore, to reduce uncertainty in the computational $k_{\mathrm{p}, \mathrm{cop}}$ plot, the computationally obtained propagation rate coefficients for the homopolymerization of MMA and BCA were not used; the experimental values for $k_{\mathrm{p}, \mathrm{MMA}}$ and $k_{\mathrm{p}, \mathrm{BCA}}$ (fitted using the procedure described above) were used instead.

The satisfactory fit of the terminal model at $50{ }^{\circ} \mathrm{C}$ prompted some additional $k_{\mathrm{p}, \text { cop }}$ measurements at 30 and $70{ }^{\circ} \mathrm{C}$ which are also presented in Figure 4 along with their corresponding terminal model fits. The confirmed invariance of BCA/MMA reactivity between 30 and $70{ }^{\circ} \mathrm{C}$ allowed the same extrapolation procedure used for the $50{ }^{\circ} \mathrm{C}$ data to be applied to the limited 30 and $70{ }^{\circ} \mathrm{C}$ data sets in order to estimate a value for $k_{\mathrm{p}, \mathrm{BCA}}$ of $226 \pm 32 \mathrm{~L} \cdot \mathrm{mol}^{-1} \cdot \mathrm{s}^{-1}$ and $475 \pm 95 \mathrm{~L} \cdot \mathrm{mol}^{-1} \cdot \mathrm{s}^{-1}$, respectively. Unfortunately, due to the current inaccessibility of a direct measure for $k_{\mathrm{p}, \mathrm{BCA}}$, and the inherent uncertainty associated with the extrapolated estimates for $k_{\mathrm{p}, \mathrm{BCA}}$, the estimation of Arrhenius parameters for BCA was not attempted. 
Table 4 Comparison of $k_{\mathrm{p}}$ for bulk BCA free-radical homopolymerization estimated in this work to other published values for ACAs and different $\alpha$ substituted acrylic monomers.

\begin{tabular}{|c|c|c|c|c|c|c|}
\hline Monomer & $\alpha$-substituent & Medium & $\begin{array}{c}\text { Temperature } \\
\left({ }^{\circ} \mathrm{C}\right)\end{array}$ & $k_{\mathrm{p}} / k_{\mathrm{p}, \text { methacrylate }}$ & $\begin{array}{c}k_{\mathrm{p}} \\
\left(\mathrm{L} \cdot \mathrm{mol}^{-1} \cdot \mathrm{s}^{-1}\right)\end{array}$ & Ref. \\
\hline \multirow{4}{*}{$n$-butyl $\alpha$-cyanoacrylate } & \multirow{4}{*}{$-\mathrm{CN}$} & Bulk & 50 & $0.55 \cdot \mathrm{MMA}$ & $379 \pm 32$ & $\mathrm{a}$ \\
\hline & & Bulk & 30 & $0.63 \cdot \mathrm{MMA}$ & $226 \pm 32$ & $\mathrm{~b}$ \\
\hline & & Bulk & 50 & $0.46 \cdot \mathrm{MMA}$ & $336 \pm 20$ & $\mathrm{~b}$ \\
\hline & & Bulk & 70 & $0.47 \cdot \mathrm{MMA}$ & $475 \pm 95$ & $\mathrm{~b}$ \\
\hline ethyl $\alpha$-cyanoacrylate & $-\mathrm{CN}$ & Bulk & 30 & $3.6 \cdot \mathrm{MMA}$ & $1610-1622$ & 13 \\
\hline$n$-butyl methacrylate & $-\mathrm{CH}_{3}$ & Bulk & 50 & - & 753 & 49 \\
\hline$n$-butyl acrylate & $-\mathrm{H}$ & Bulk & 52 & $39.5 \cdot \mathrm{BMA}$ & 29774 & 50 \\
\hline ethyl $\alpha$-hydroxy methacrylate & $-\mathrm{CH}_{2} \mathrm{OH}$ & Solution & 15 & $2.5-8.3 \cdot$ EMA & $580-1860$ & 46,51 \\
\hline
\end{tabular}

In Table 4, the extrapolated estimates of $k_{\mathrm{p}, \mathrm{BCA}}$ at 30,50 , and $70{ }^{\circ} \mathrm{C}$ are compared to the only other available ACA $k_{\mathrm{p}}$ estimate in the literature as well as the $k_{\mathrm{p}}$ estimates for other acrylic monomers differing in $\alpha$-substituent. Although some of the $k_{\mathrm{p}}$ values are for monomers whose alkyl chain lengths are shorter than that of BCA, the results are still comparable, as an increase in alkyl chain length leads to only a slight increase in $k_{\mathrm{p}}$ for methacrylates. ${ }^{20}$ To compensate for differences in experimental conditions and techniques, the $k_{\mathrm{p}}$ values of the $\alpha$ substituted monomers are expressed relative to the $k_{\mathrm{p}}$ of their methacrylate analogs. Included in the table is the study of Yamada et al. that measured both $k_{\mathrm{p}, \mathrm{ECA}}$ and $k_{\mathrm{p}, \mathrm{MMA}}$ in bulk at $30{ }^{\circ} \mathrm{C}$ using the rotating sector method. Their results indicate that the free-radical polymerization of ECA is 3.6 times faster than MMA. $^{13}$ Although their finding is supported by the computational work of Değirmenci et al., ${ }^{16}$ in this work BCA is estimated to have a $k_{\mathrm{p}}$ approximately $50 \%$ lower than that of MMA between 30 and $70{ }^{\circ} \mathrm{C}$. Despite the fact that these estimates for $k_{\mathrm{p}, \mathrm{BCA}}$ are extrapolated values, it is clear from the $k_{\mathrm{p} \text {,cop }}$ data in Figure 4 that $k_{\mathrm{p}, \mathrm{BCA}}$ should be lower or similar to $k_{\mathrm{p}, \mathrm{MMA}}$, contrary to the previously published value of Yamada et al. for ECA. ${ }^{13}$ This conclusion is supported by the pure computational value for $k_{\mathrm{p}, \mathrm{BCA}}$ in Table 3 which is more than one order of magnitude lower than $k_{\mathrm{p}, \mathrm{MMA}}$; as was already pointed out, the prediction of absolute values by QM calculation may be subject to uncertainties arising from the approximations adopted during the computational analysis. ${ }^{45}$

The two electron withdrawing groups, $-\mathrm{CN}$ and $-\mathrm{COOR}$, which are responsible for the renowned reactivity of the anionic polymerization of ACAs, do not result in the same effect on the FRP of BCA. The presence of these two electron withdrawing groups increases the lability of the hydrogen atom on the adjacent vinyl carbon leading to the generation of a stable and poorly reactive BCA radical. The activation energy values in Table 3, corresponding to the addition reactions of either monomer to BCA or MMA radicals, confirm the lower reactivity of BCA radicals relative to MMA radicals. On the other hand, the MMA radical cross-propagation rate coefficient in Table 3 shows that, compared to MMA radical homopropagation, the $-\mathrm{CN}$ electron-withdrawing substituent at the $\alpha$ position clearly facilitates an elevated level of BCA monomer incorporation into the growing polymer chain. Moreover, this rapid cross-propagation is evidenced in Figure 4 by the high $k_{\mathrm{p} \text {,cop }}$ values for copolymerizations with initial compositions rich in MMA (i.e. for copolymerizations with $0.50 \leq f_{\mathrm{MMA}} \leq$ 0.97 , the $k_{\mathrm{p}, \text { cop }}$ is at least double the experimental $k_{\mathrm{p}, \mathrm{MMA}}$ value at $50{ }^{\circ} \mathrm{C}$ ). However, the Arrhenius parameters for the BCA radical reaction couples do not lead to the same conclusion. In particular, the low computational estimate of $k_{\mathrm{p}, \mathrm{BCA}}$ indicates that the addition of BCA monomer to $\mathrm{BCA}$ radical is up to 4 times less favorable than the addition of MMA monomer to BCA radical. The increased difficulty in BCA radical homopropagation compared to cross-propagation is more likely attributed to the mutual repulsion between dipolar $-\mathrm{CN}$ groups than a steric effect. Morrison and Davis found that despite the increased bulkiness of the hydroxymethyl group at the $\alpha$ position, the $k_{\mathrm{p}}$ for ethyl $\alpha$-hydroxy methacrylate (EHMA) is 2.5-8.3 times that of ethyl methacrylate (EMA) at $15{ }^{\circ} \mathrm{C}$ and is strongly dependent on solvent choice. ${ }^{46}$ A computational approach by Dogan et al. explained this surprising observation based on intra- and inter-molecular hydrogen bonding of EHMA monomers and growing radical chains which can be disrupted or enhanced through solvent choice, ${ }^{47}$ an effect which has been well-documented for the FRP kinetics of its structural isomer 2-hydroxyethyl methacrylate (HEMA). ${ }^{48}$ These two contrasting examples demonstrate that the identity of the $\alpha$ substituent manifests special kinetic considerations beyond the typical acrylate FRP kinetic scheme that requires further study to improve understanding. An investigation aimed at solvent effects on the BCA/MMA copolymerization kinetics system could be useful to gain insight into the $-\mathrm{CN}$ group's dual impact on FRP propagation kinetics, and to see if solvent choice can be used to further manipulate polymer final properties.

\section{Conclusions}

In this work, the PLP-SEC technique was applied to study the FRP propagation kinetics of the $n$-butyl cyanoacrylate (BCA) and methyl methacrylate (MMA) copolymerization system in bulk at 30,50 , and $70{ }^{\circ} \mathrm{C}$ with $1 \mathrm{v} \%$ DCAA to suppress the 
anionic polymerization of BCA. Low-conversion FRPgenerated copolymers were successfully isolated without inducing the rapid anionic polymerization of residual BCA monomer using methanol containing $5 \mathrm{v} \%$ methacrylic acid at room temperature. This procedure enabled an accurate and highly reproducible ${ }^{1} \mathrm{H}-\mathrm{NMR}$ copolymer composition analysis for copolymers produced from initial monomer compositions up to $f_{\mathrm{BCA}}=0.85$. A Mayo-Lewis plot was constructed and fitted to the $50{ }^{\circ} \mathrm{C}$ data with reactivity ratio estimates of $r_{\mathrm{BCA}}=0.236$ \pm 0.042 and $r_{\mathrm{MMA}}=0.057 \pm 0.008$, in excellent agreement with the experimental copolymer composition data at 30 and $70{ }^{\circ} \mathrm{C}$ as well as the values $\left(r_{\mathrm{BCA}}=0.272\right.$ and $\left.r_{\mathrm{MMA}}=0.057\right)$ predicted by Quantum Mechanics at $50{ }^{\circ} \mathrm{C}$. This confirms and clarifies that BCA/MMA copolymerization is well-represented by the terminal model as a strongly alternating system over the 30-70 ${ }^{\circ} \mathrm{C}$ temperature range.

Reliable estimates for bulk $k_{\mathrm{p}, \text { cop }}$ at $50{ }^{\circ} \mathrm{C}$ were determined from low-conversion PLP experiments as a function of comonomer composition (up to $f_{\mathrm{BCA}}=0.85$ ) with excellent agreement between estimates made from RI and LS detectors as well as samples produced from the same composition at different repetition rates. Since a direct estimate for $k_{\mathrm{p}, \mathrm{BCA}}$ could not be obtained experimentally, the $k_{\mathrm{p} \text {,cop }}$ data were fitted to the terminal model using reactivity ratios predicted by Quantum Mechanics and determined by experimental composition analysis to extrapolate estimates for bulk $k_{\mathrm{p} . \mathrm{BCA}}$ at $50{ }^{\circ} \mathrm{C}$ of 379 $\pm 32 \mathrm{~L} \cdot \mathrm{mol}^{-1} \cdot \mathrm{s}^{-1}$ and $336 \pm 20 \mathrm{~L} \cdot \mathrm{mol}^{-1} \cdot \mathrm{s}^{-1}$, respectively. These results, supported by smaller sets of $k_{\mathrm{p}, \mathrm{cop}}$ experiments performed at 30 and $70{ }^{\circ} \mathrm{C}$, indicate that $k_{\mathrm{p}, \mathrm{BCA}}$ is about $50 \%$ the value of $k_{\mathrm{p}, \mathrm{MMA}}$, contrary to the previously published value of $3.6 \cdot k_{\mathrm{p}, \mathrm{MMA}}$ for $k_{\mathrm{p}, \mathrm{ECA}}$ at $30{ }^{\circ} \mathrm{C} .{ }^{13}$

Future FRP kinetics experimental investigations in solution as well as Molecular Dynamics simulations should be conducted to determine if solvent choice can be used to better understand the two characteristics of the $-\mathrm{CN}$ group at the $\alpha$ position which seem to have opposing effects on FRP: dipolarity (mutual repulsion during homo-propagation) and electron withdrawing (increased reactivity of vinyl group towards attack by a methacrylate radical). Furthermore, ACA copolymerization studies should be extended to other comonomers such as styrene, acrylates, and functional monomers to access a wider range of materials and control their diverse final properties.

In their Expert Opinion Review, Graf et al. identified the incomplete control over factors influencing polymerization kinetics as a prime contributor to the lack of reproducibility of the in vitro and in vivo results for PACA colloidal carriers. ${ }^{6}$ Although most PACA NPs are produced anionically, the improved knowledge of PACA formation through FRP can be used to better understand final PACA properties relevant to biological applications. Thus, this detailed investigation of the FRP kinetics for BCA/MMA copolymerization has not only updated our understanding of ACA systems in general, but has also demonstrated that a high level of control over MW and degradation can now be achieved.

\section{Acknowledgements}

Funding from the Natural Science and Engineering Research Council of Canada, the European Union Seventh Framework Programme [FP7/2007-2013] under grant agreement number 238013, the Scientific Grant Agency of the Ministry of Education, science, research and sport of the Slovak Republic and the Slovak Academy of Sciences under grant agreement VEGA 2/0198/14 are gratefully acknowledged. We also thank Eva Hipká and Anna Chovancová at the Polymer Institute of the Slovak Academy of Sciences for their experimental assistance and expertise.

\section{Notes and references}

a Department of Chemical Engineering, Dupuis Hall, Queen's University, Kingston, Ontario K7L 3N6, Canada; E-mail: robin.hutchinson@queensu.ca

${ }^{b}$ Department of Chemistry, Materials and Chemical Engineering "Giulio Natta”, Politecnico di Milano, Via Luigi Mancinelli 7, 20131 Milano, Italy; E-mail: davide.moscatelli@polimi.it

${ }^{c}$ Polymer Institute of the Slovak Academy of Sciences, Dúbravska cesta 9, 84541 Bratislava 45, Slovakia; E-mail: igor.lacik@savba.sk

$\dagger$ Electronic Supplementary Information (ESI) available: Details for PLP experimental conditions, ${ }^{1} \mathrm{H}-\mathrm{NMR}$ analysis, and QM calculations. See DOI: $10.1039 / \mathrm{b} 000000 \mathrm{x} /$

1 C. Limouzin, A. Caviggia, F. Ganachaud and P. Hémery, Macromolecules 2003, 36, 667.

2 M. Dossi, G. Storti and D. Moscatelli, Macromol. Symp. 2010, 289, 124.

3 E. M. Petrie, Handbook of Adhesives \& Sealants; Mcgrawhill, 1999.

4 F. Elias, M. T. Peracchia and P. Couvreur, Handbook of Biodegradable Polymers; CRC Press: 1998.

5 P. Couvreur, B. Kante, M. Roland and P. Speiser, J. Pharm. Sci. 1979, 68, 1521.

6 A. Graf, A. McDowell and T. Rades, Expert Opin. Drug Del. 2009, 6, 371 .

7 J. Nicolas and P. Couvreur, Wiley Interdiscip. Rev. Nanomed. and Nanobiotechnol. 2009, 1, 111.

8 P. Couvreur, B. Kante, M. Roland, P. Guiot, P. Bauduin and P. Speiser, J. Pharm. Pharmacol. 1979, 31, 331.

9 M. G. Han, S. Kim and S. X. Liu, Polym. Degrad. Stab. 2008, 93, 1243.

10 D. R. Robello, T. D. Eldridge and M. T. Swanson, J. Polym. Sci., Part A: Polym. Chem. 1999, 37, 4570.

11 B. Ryan and G. McCann, Macromol. Rapid Commun. 1996, 17, 217.

12 M. G. Han and S. Kim, Polymer 2009, 50, 1270.

13 B. Yamada, M. Yoshioka and T. Otsu, Makromol. Chem. 1983, 184, 1025.

14 B. Yamada, T. Hayashi and T. Otsu, J. Macromol. Sci. Pure Appl. Chem. 1983, 19, 1023.

15 B. Yamada, T. Kontani, M. Yoshioka and T. Otsu, J. Polym. Sci., Part A: Polym. Chem. 1984, 22, 2381.

16 I. Değirmenci, V. Aviyente, V. Van Speybroeck and M. Waroquier, Macromolecules 2009, 42, 3033. 
17 A. J. Canale, W. E. Goode, J. B. Kinsinger, J. R. Panchak, R. L. Kelso, and R. K. Graham, J. Appl. Polym. Sci. 1960, 4, 231.

18 S. Beuermann, M. Buback, T. P. Davis, R. G. Gilbert, R. A. Hutchinson, O. F. Olaj, G. T. Russell, J. Schweer and A. M. van Herk, Macromol. Chem. Phys. 1997, 198, 1545.

19 S. Beuermann and M. Buback, Prog. Polym. Sci. 2002, 27, 191.

20 S. Beuermann, M. Buback, T. P. Davis, R. G. Gilbert, R. A. Hutchinson, A. Kajiwara, B. Klumperman and G. T. Russell, Macromol. Chem. Phys. 2000, 201, 1355.

21 J. M. Asua, S. Beuermann, M. Buback, P. Castignolles, B. Charleux, R. G. Gilbert, R. A. Hutchinson, J. R. Leiza, A. N. Nikitin, J. P. Vairon and A. M. van Herk, Macromol. Chem. Phys. 2004, 205, 2151.

22 R. A. Hutchinson, J. H. McMinn, D. A. Paquet, S. Beuermann and C. Jackson, Ind. Eng. Chem. Res. 1997, 36, 1103.

23 J. B. Kinsinger, J. R. Panchak, R. L. Kelso, J. S. Bartlett and R. K. Graham, J. Appl. Polym. Sci. 1965, 9, 429.

24 F. R. Mayo and F. M. Lewis, J. Amer. Chem. Soc. 1944, 66, 1594.

25 A. P. Haehnel, M. Stach, A. Chovancova, J. M. Rueb, G. Delaittre, A. M. Misske, I. Lacik and C. Barner-Kowollik, Polym. Chem. 2014, 5, 862.

26 R. A. Hutchinson, D. A. Paquet, J. H. McMinn, S. Beuermann, R. E. Fuller and C. Jackson, DECHEMA Monogr. 1995, 131, 467.

27 M. Dossi, K. Liang, R. A. Hutchinson and D. Moscatelli, J. Phys. Chem. B 2010, 114, 4213.

28 R. A. Hutchinson, J. H. McMinn, D. A. Paquet, S. Beuermann and C. Jackson, Ind. Eng. Chem. Res. 1997, 36, 1103.

29 E. F. Donnelly and D. C. Pepper, Makromol. Chem., Rapid Commun. 1981, 2, 439.

30 T. Fukuda, K. Kubo and Y. D. Ma, Prog. Polym. Sci. 1992, $17,875$.

31 A. D. Becke, J. Chem. Phys. 1993, 98, 5648.

32 C. T. Lee, W. T. Yang and R. G. Parr, Phys. Rev. B 1988, 37,785 .

33 Y. Zhao and D. G. Truhlar, J. Phys. Chem. A 2004, 108, 6908.

34 X. Yu, S. E. Levine and L. J. Broadbelt, Macromolecules 2008, 41, 8242.

35 E. Mavroudakis, D. Cuccato, M. Dossi, G. Comino and D. Moscatelli, Phys. Chem. A 2014, 118, 238.

36 D. Cuccato, E. Mavroudakis, M. Dossi and D. Moscatelli, Macromol. Theory Simul. 2013, 22, 127.

37 D. Cuccato, E. Mavroudakis and D. Moscatelli, J. Phys. Chem. A 2013, 117, 4358.

38 E. Mavroudakis, D. Cuccato and D. Moscatelli, J. Phys. Chem. A 2014, 118, 1799.

39 E. Mavroudakis, D. Cuccato and D. Moscatelli, Ind. Eng. Chem. Res. 2014, 53, 9058.

40 Yu, X. R.; Broadbelt, L. J. Macromol. Theory Simul. 2012, $21,461$.

41 Gaussian 09, M. J. Frisch, G. W. Trucks, H. B. Schlegel, G. E. Scuseria, M. A. Robb, J. R. Cheeseman, G. Scalmani, V.
Barone, B. Mennucci, G. A. Petersson, H. Nakatsuji, M. Caricato, X. Li, H. P. Hratchian, A. F. Izmaylov, J. Bloino, G. Zheng, J. L. Sonnenberg, M. Hada, M. Ehara, K. Toyota, R. Fukuda, J. Hasegawa, M. Ishida, T. Nakajima, Y. Honda, O. Kitao, H. Nakai, T. Vreven, J. A. Montgomery, Jr., J. E. Peralta, F. Ogliaro, M. Bearpark, J. J. Heyd, E. Brothers, K. N. Kudin, V. N. Staroverov, R. Kobayashi, J. Normand, K. Raghavachari, A. Rendell, J. C. Burant, S. S. Iyengar, J. Tomasi, M. Cossi, N. Rega, J. M. Millam, M. Klene, J. E. Knox, J. B. Cross, V. Bakken, C. Adamo, J. Jaramillo, R. Gomperts, R. E. Stratmann, O. Yazyev, A. J. Austin, R. Cammi, C. Pomelli, J. W. Ochterski, R. L. Martin, K. Morokuma, V. G. Zakrzewski, G. A. Voth, P. Salvador, J. J. Dannenberg, S. Dapprich, A. D. Daniels, Ö. Farkas, J. B. Foresman, J. V. Ortiz, J. Cioslowski and D. J. Fox, Gaussian, Inc., Wallingford CT, 2009.

42 N. Markova, G. Ivanova, V. Enchev and M. Simeonova, Struct. Chem. 2012, 23, 815.

43 M. Dossi and D. Moscatelli, Macromol. React. Eng. 2012, 6,74 .

44 E. Mavroudakis, K. Liang, D. Moscatelli and R. A. Hutchinson, Macromol. Chem. Phys. 2012, 213, 1706.

45 X. R. Yu, S. E. Levine and L. J. Broadbelt, Macromolecules 2008, 41, 8242.

46 D. A. Morrison and T. P. Davis, Macromol. Chem. Phys. 2000, 201, 2128.

47 B. Dogan, S. Catak, V. Van Speybroeck, M. Waroquier and V. Aviyente, Polymer 2012, 53, 3211.

48 K. Liang, T. R. Rooney and R. A. Hutchinson, Ind. Eng. Chem. Res. 2014, 53, 7296.

49 S. Beuermann and M. Buback, Pure Appl. Chem. 1998, 70, 1415.

50 C. Barner-Kowollik, F. Günzler and T. Junkers, Macromolecules 2008, 41, 8971.

51 M. D. Zammit, M. L. Coote, T. P. Davis and G. D. Willett, Macromolecules 1998, 31, 955. 


\section{Supporting Information}

\section{Pulsed-laser and Quantum Mechanics Study of $n$-Butyl Cyanoacrylate and Methyl Methacrylate Free-Radical Copolymerization}

Thomas R. Rooney, ${ }^{\mathrm{a}}$ Evangelos Mavroudakis, ${ }^{\mathrm{b}}$ Igor Lacík, ${ }^{\mathrm{c}}$ Robin A. Hutchinson ${ }^{*^{\mathrm{a}}}$ and Davide Moscatelli*b

\section{Copolymer Composition Characterization.}

When methanol $(\mathrm{MeOH})$ containing $5 \mathrm{v} \%$ methacrylic acid (MAA) is used to treat the PLP reaction mixture the FRP-generated copolymer can be successfully isolated devoid of anionic PBCA. A

typical ${ }^{1} \mathrm{H}-\mathrm{NMR}$ spectrum of the isolated copolymer is shown in Figure S1. The total moles of copolymer can be measured using two separate methods, represented by Equations S1 and S2, which are derived from three independent signals such that three independent estimates of copolymer composition can be made per sample via Equations S3, S4, and S5. The peak integration used to formulate Equation S1 comprises an overlap of signals with identical multiplicities originating from both methyl methacrylate (MMA) and $n$-butyl cyanoacrylate (BCA) pendant chains. By comparing Equations S1 and S2 one can see that the presence of any anionic PBCA will lead to a distinct disagreement between the two measures and consequently an unreliable estimate of copolymer composition. The three calculations are summarized in Table S1 for a range of initial BCA content samples. The estimate from Equation S3 was used for the Mayo-Lewis plot in the Results and Discussion section because it derives from one independent peak of each pendant chain.

$$
\begin{aligned}
& \text { Pol }_{\text {Total }, 1}=\frac{\text { Peak }(d+q)}{3} \\
& \text { Pol }_{\text {Total }, 2}=\frac{\text { Peak } a}{2}+\frac{\text { Peake }}{3} \\
& F_{B C A}(S 3)=\frac{\frac{\text { Peak } a}{2}}{\text { Pol }} \text { Total, } \\
& F_{B C A}(S 4)=\frac{\frac{\text { Peak } a}{2}}{\text { Pol }_{\text {Total }, 1}}
\end{aligned}
$$




$$
F_{B C A}(S 5)=1-\frac{\frac{\text { Peake }}{3}}{\text { Pol }_{\text {Total }, 1}}
$$

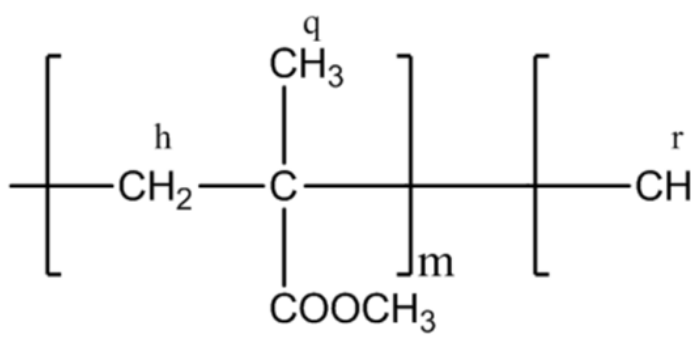

e

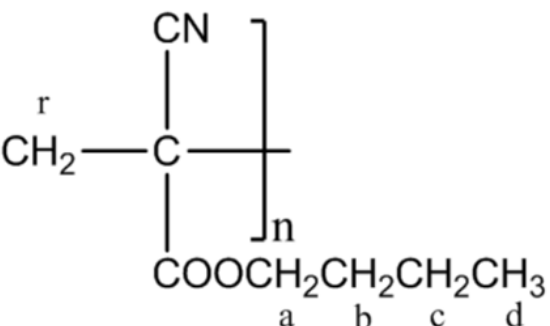

a b c d
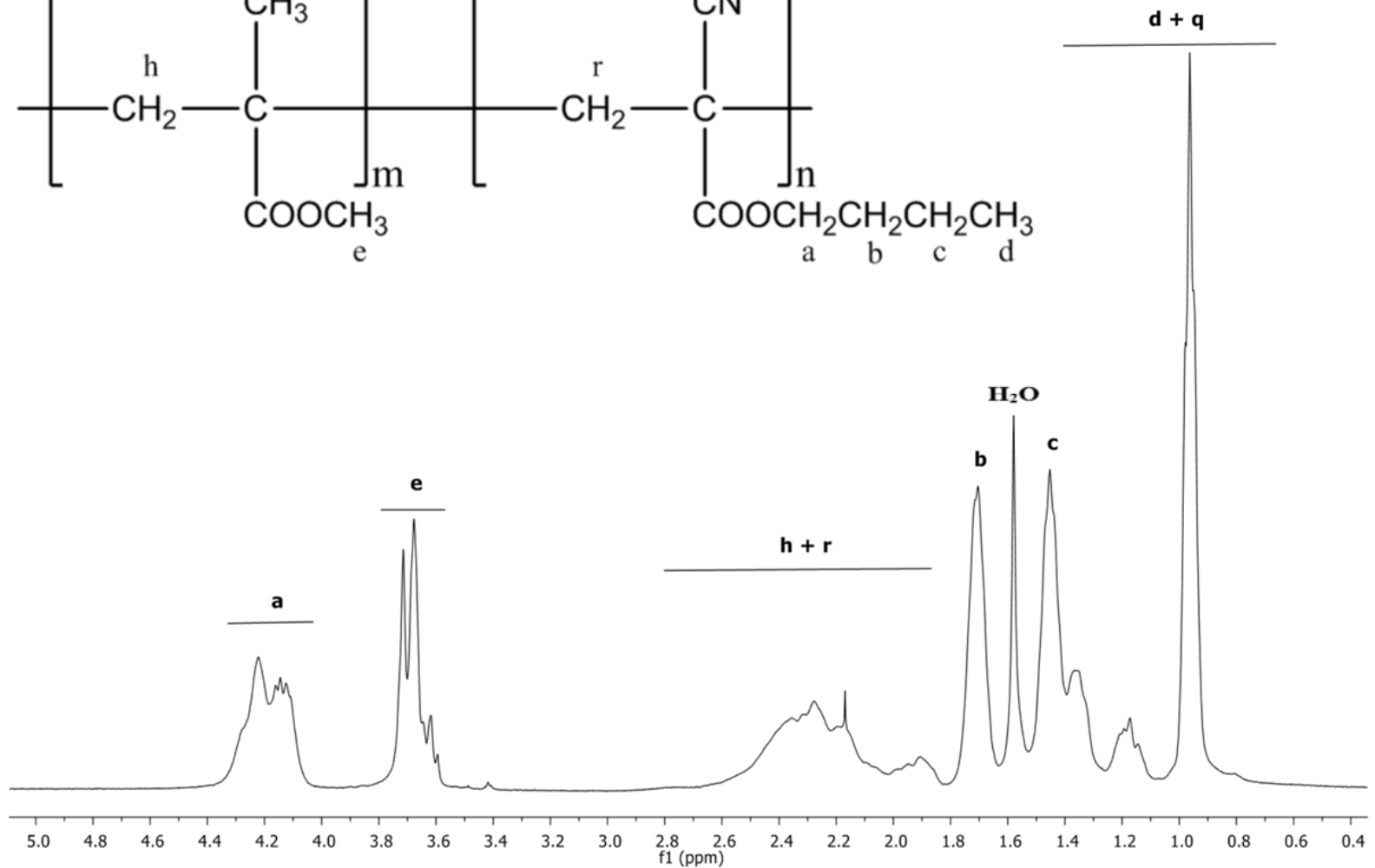

Figure S1 ${ }^{1} \mathrm{H}-\mathrm{NMR}$ spectrum in $\mathrm{CDCl}_{3}$ for a low-conversion $(1.3 \%)$ copolymer in which inadvertent anionic polymerization of BCA monomer was successfully suppressed during FRP and the copolymer isolation procedure. The copolymer was produced from $f_{\mathrm{BCA}}=0.72$ in bulk at $50{ }^{\circ} \mathrm{C}$ at $50 \mathrm{~Hz}$ with $1 \mathrm{v} \%$ DCAA and $5 \mathrm{mmol} \cdot \mathrm{L}^{-1}$ DMPA. Sample precipitation performed in $\mathrm{MeOH}$ containing $5 \mathrm{v} \%$ MAA at room temperature.

Table S1 Summary of three independent copolymer composition estimations made per lowconversion BCA/MMA copolymer generated at various temperatures by PLP.

\section{Temperature}

$\left({ }^{\circ} \mathrm{C}\right)$
$F_{\text {BCA }}(\mathrm{S} 3)$
Consistency Checks

$f_{\mathrm{BCA}}$

50

$$
F_{\text {BCA }}(\mathrm{S} 4)
$$

0.03

0.07

0.14

0.14

0.14
0.30

0.34

0.43

0.41

0.45
$F_{\text {BCA }}(\mathrm{S} 5)$ 


\begin{tabular}{|c|c|c|c|c|}
\hline & 0.22 & 0.47 & 0.49 & 0.44 \\
\hline & 0.22 & 0.47 & 0.47 & 0.47 \\
\hline & 0.22 & 0.46 & 0.43 & 0.50 \\
\hline & 0.30 & 0.50 & 0.50 & 0.51 \\
\hline & 0.40 & 0.51 & 0.49 & 0.52 \\
\hline & 0.40 & 0.50 & 0.48 & 0.52 \\
\hline & 0.40 & 0.50 & 0.46 & 0.53 \\
\hline & 0.40 & 0.52 & 0.54 & 0.49 \\
\hline & 0.50 & 0.55 & 0.55 & 0.56 \\
\hline & 0.50 & 0.56 & 0.56 & 0.56 \\
\hline & 0.50 & 0.54 & 0.53 & 0.55 \\
\hline & 0.60 & 0.60 & 0.59 & 0.60 \\
\hline & 0.60 & 0.63 & 0.65 & 0.62 \\
\hline & 0.72 & 0.61 & 0.57 & 0.63 \\
\hline & 0.72 & 0.63 & 0.64 & 0.62 \\
\hline & 0.72 & 0.63 & 0.61 & 0.64 \\
\hline & 0.85 & 0.68 & 0.66 & 0.68 \\
\hline & 0.85 & 0.68 & 0.66 & 0.70 \\
\hline & 0.85 & 0.68 & 0.67 & 0.68 \\
\hline \multirow[t]{5}{*}{30} & 0.03 & 0.31 & 0.29 & 0.33 \\
\hline & 0.07 & 0.38 & 0.35 & 0.42 \\
\hline & 0.14 & 0.45 & 0.42 & 0.48 \\
\hline & 0.22 & 0.48 & 0.46 & 0.50 \\
\hline & 0.50 & 0.54 & 0.51 & 0.57 \\
\hline \multirow[t]{4}{*}{70} & 0.03 & 0.28 & 0.27 & 0.30 \\
\hline & 0.14 & 0.43 & 0.45 & 0.41 \\
\hline & 0.40 & 0.53 & 0.49 & 0.56 \\
\hline & 0.85 & 0.69 & 0.66 & 0.70 \\
\hline
\end{tabular}




\section{Composition-averaged Copolymer Propagation Rate Coefficient Estimation}

Dichloroacetic acid (DCAA) is added in the amount of $1 \mathrm{v} \%$ to each BCA/MMA reaction mixture to suppress the anionic polymerization of BCA during the PLP experiment. In order to confirm that the presence of DCAA does not have an influence on the FRP kinetics of the BCA/MMA system, a set of PLP copolymerization experiments $\left(f_{\mathrm{BCA}}=0.03\right)$ were performed in bulk at $50{ }^{\circ} \mathrm{C}$ and $50 \mathrm{~Hz}$ in which the amount of DCAA was systematically varied from 0.1 to $3.0 \mathrm{v} \%$. Furthermore, MMA bulk homopolymerizations at $50{ }^{\circ} \mathrm{C}$ and $50 \mathrm{~Hz}$ were conducted with 0 and $1 \mathrm{v} \%$ DCAA as well. The MWDs from these PLP-SEC experiments are presented in Figure S2 and do not demonstrate any significant dependence on DCAA content. This conclusion is supported by the results in Table $\mathrm{S} 2$ which show that there is no significant variation in $k_{\mathrm{p}, \mathrm{cop}}$ or $k_{\mathrm{p}, \mathrm{MMA}}$ with DCAA content.

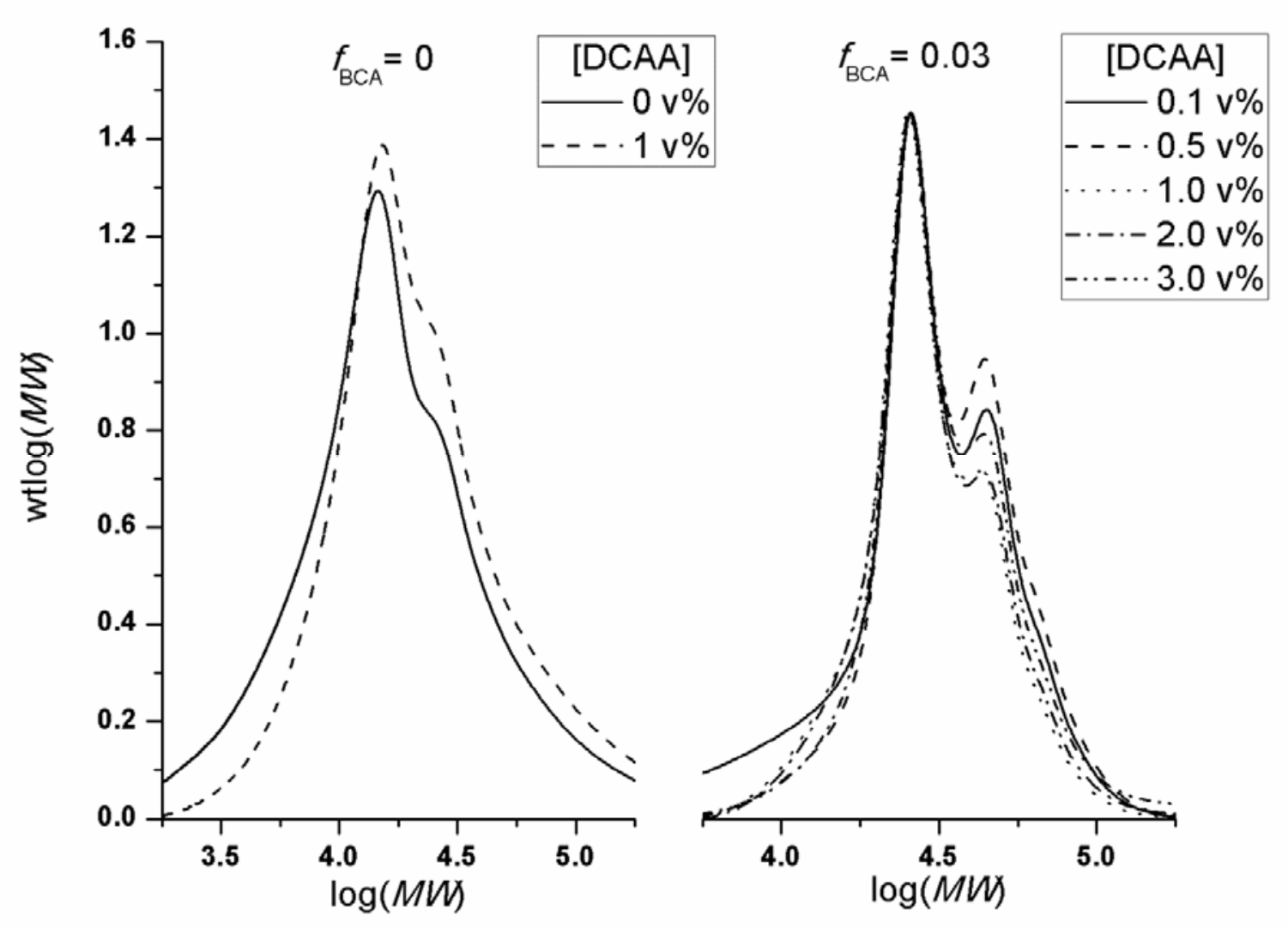

Figure S2 Effect of [DCAA] on MWDs generated from PLP experiments performed in bulk at 50 ${ }^{\circ} \mathrm{C}$ and $50 \mathrm{~Hz}$ with $5 \mathrm{mmol} \cdot \mathrm{L}^{-1} \mathrm{DMPA}$. 
Table S2 Effect of the presence of DCAA during PLP experiments performed at $50 \mathrm{~Hz}$ and $50{ }^{\circ} \mathrm{C}$. Results are presented from RI detector relative to $k_{\mathrm{p}}$ estimated for MMA without any DCAA under identical operating conditions.

\begin{tabular}{ccc}
\hline \multirow{2}{*}{ DCAA content $(\% \mathrm{v})$} & \multicolumn{2}{c}{$k_{\mathrm{p}, \mathrm{cop}}([\mathrm{DCAA}]) / k_{\mathrm{p}, \mathrm{MMA}}$} \\
\cline { 2 - 3 } & $f_{\mathrm{BCA}}=0.03$ & $f_{\mathrm{BCA}}=0$ \\
\hline 0.0 & 1.98 & - \\
0.1 & 1.95 & - \\
0.5 & 1.95 & 1.02 \\
1.0 & 1.99 & - \\
2.0 & 2.01 & - \\
3.0 & & \\
\hline
\end{tabular}

The estimates which were deemed reliable from the BCA/MMA PLP-SEC experiments, performed at $50{ }^{\circ} \mathrm{C}$ with $1 \mathrm{v} \%$ DCAA and $5 \mathrm{mmol} \cdot \mathrm{L}^{-1} \mathrm{DMPA}$, to construct the $k_{\mathrm{p}, \text { cop }}$ plot in the Results and Discussion section and subsequently used to extrapolate an estimated value for $k_{\mathrm{p}, \mathrm{BCA}}$ are presented in Table S4. Although FRP polymer was recovered from $f_{\mathrm{BCA}}=0.93$ PLP experiments and ${ }^{1} \mathrm{H}-\mathrm{NMR}$ analysis confirmed the incorporation of some MMA units, the amount and sensitivity of contaminant PBCA production is overwhelming and prevents accurate $k_{\mathrm{p}, \text { cop }}$ estimation even from an array of different operating conditions. Figure S3 illustrates the difficulties in obtaining PLP structure from high $f_{\mathrm{BCA}}$ samples in which the sample pulsed at $20 \mathrm{~Hz}$ was divided into two. One half was treated with a volume of precipitation solution (denoted by *) twice that of the other. When the amount of $\mathrm{MeOH}$ solution is doubled at $-10{ }^{\circ} \mathrm{C}$ the high $\mathrm{MW}$ contaminant PBCA peak becomes more prominent and the low MW PLP structure is lost (remains in solution). The inflection point locations are provided in Table S3 and indicate that the $k_{\mathrm{p}, \text { cop }}$ for $f_{\mathrm{BCA}}=0.93$ is between 349 and 503 $\mathrm{L} \cdot \mathrm{mol}^{-1} \cdot \mathrm{s}^{-1}$. Although this cannot be confirmed it is still consistent with the trend shown for the $k_{\mathrm{p}, \mathrm{cop}}$ plot in the Results and Discussion section. 


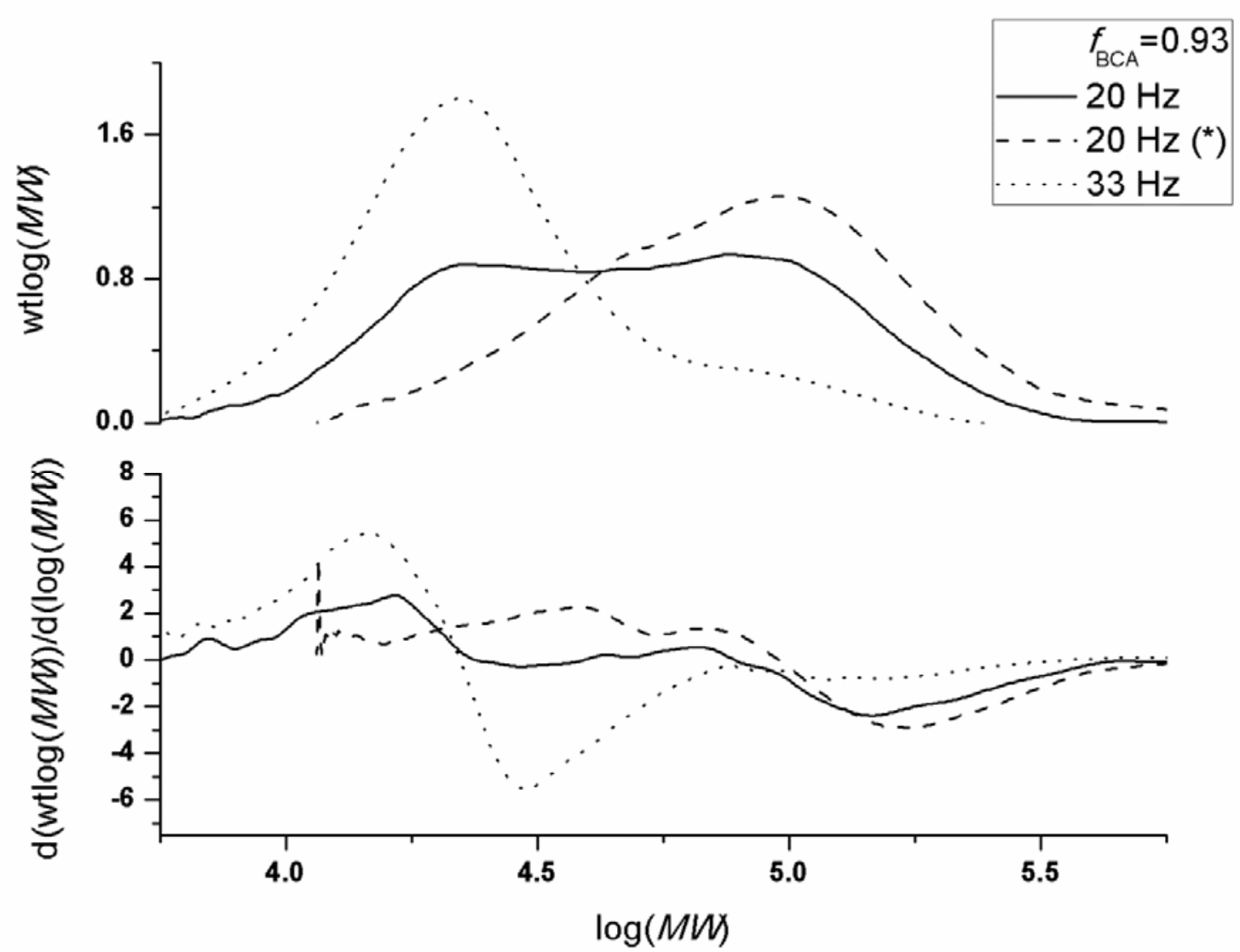

Figure S3 MWDs and $1^{\text {st }}$ derivative plots for bulk BCA/MMA with $1 \mathrm{v} \%$ DCAA and $5 \mathrm{mmol} \cdot \mathrm{L}^{-1}$ DMPA pulsed from $f_{\mathrm{BCA}}=0.93$ at $50{ }^{\circ} \mathrm{C}$. All samples were precipitated in $\mathrm{MeOH}$ containing $5 \mathrm{v} \%$ MAA at $-10{ }^{\circ} \mathrm{C}$. ${ }^{*}$ indicates that twice the volume of precipitation solution was used to treat the sample.

Table S3 Inflection points corresponding to $1^{\text {st }}$ Derivative plots in Figure S2 for $f_{\mathrm{BCA}}=0.93$ pulsed at $50{ }^{\circ} \mathrm{C}$ with $1 \mathrm{v} \%$ DCAA and $5 \mathrm{mmol} \cdot \mathrm{L}^{-1}$. Samples were precipitated in $\mathrm{MeOH}$ containing $5 \mathrm{v} \%$ MAA at $-10{ }^{\circ} \mathrm{C}$. * indicates that twice the volume of precipitation solution was used to treat the sample.

\begin{tabular}{ccccccc}
\hline & $\begin{array}{c}\mathrm{M}_{1} \\
\left(\mathrm{~g} \cdot \mathrm{mol}^{-1}\right)\end{array}$ & $\begin{array}{c}\mathrm{M}_{2} \\
\left(\mathrm{~g} \cdot \mathrm{mol}^{-1}\right)\end{array}$ & $\begin{array}{c}\mathrm{M}_{3} \\
\left(\mathrm{~g} \cdot \mathrm{mol}^{-1}\right)\end{array}$ & $\mathrm{M}_{2} / \mathrm{M}_{1}$ & $\mathrm{M}_{3} / \mathrm{M}_{2}$ & $\begin{array}{c}k_{\mathrm{p}, \text { cop }} \text { from } \\
\mathrm{M}_{1}\left(\mathrm{~L} \cdot \mathrm{mol}^{-}\right. \\
1\end{array}$ \\
\hline $20 \mathrm{~Hz}$ & 16654 & 43733 & 66100 & 2.63 & 1.51 & 349 \\
$20 \mathrm{~Hz} *$ & 38473 & 68470 & - & 1.78 & - & 806 \\
$33 \mathrm{~Hz}$ & 14537 & 76213 & - & 5.24 & - & 503 \\
\hline
\end{tabular}


A direct estimate of $k_{\mathrm{p}, \mathrm{BCA}}$ was not possible because the homopolymer undergoes depolymerization in THF while awaiting SEC analysis (even when the PLP reaction mixture is spiked with 2500 ppm MMA). As shown in Figure S4, MWDs without PLP features are obtained even when the PLP experiment is performed at $75{ }^{\circ} \mathrm{C}$ and $10 \mathrm{~Hz}$ (although in this case a degraded PLP distribution is apparent). At $50{ }^{\circ} \mathrm{C}$ there is only a high MW population and oligomers which is consistent with depolymerization-repolymerization behaviour.

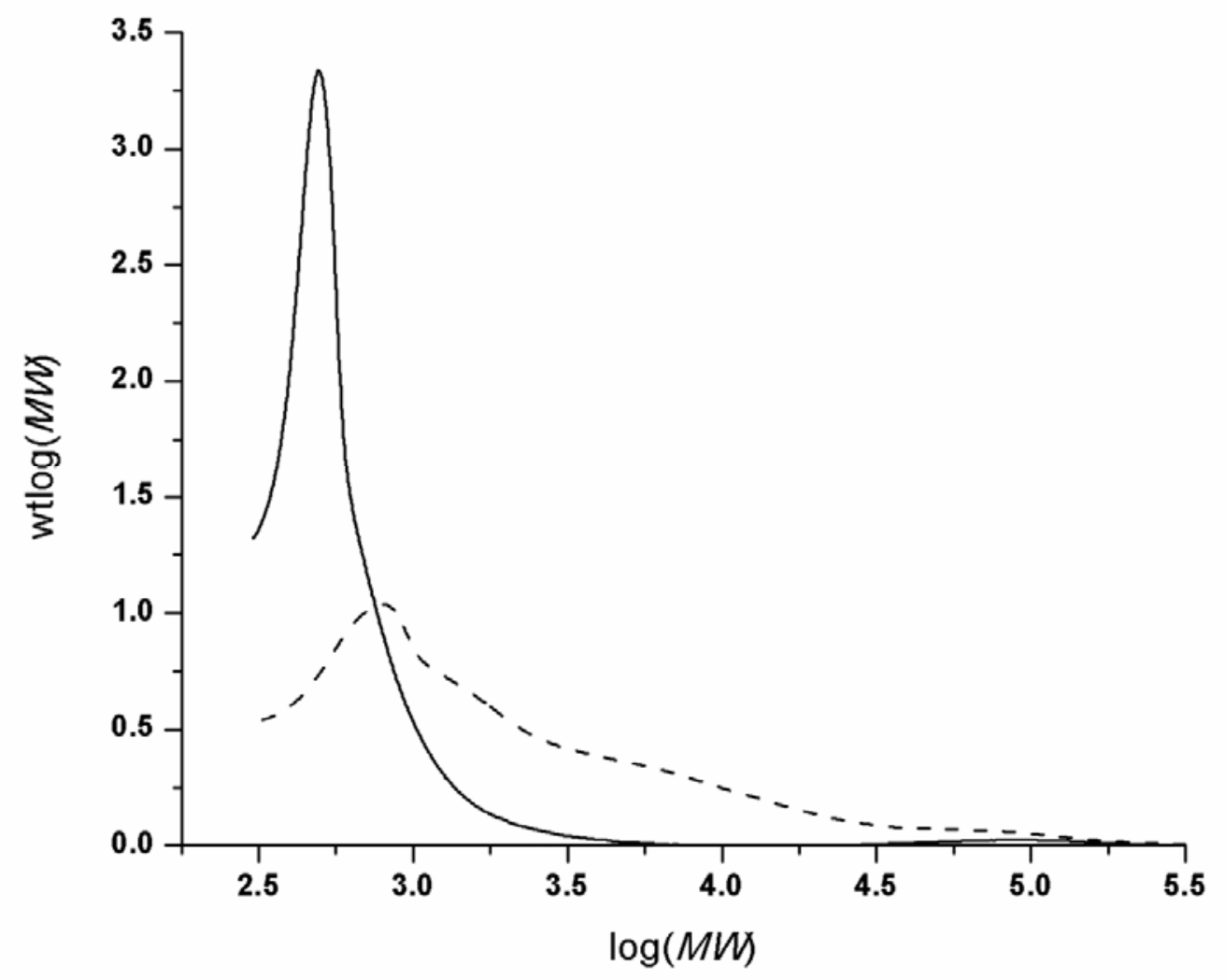

Figure S4 MWDs for BCA homopolymerization at $50{ }^{\circ} \mathrm{C}$ (solid line) and $75{ }^{\circ} \mathrm{C}$ (dashed line) $1 \mathrm{v} \%$ DCAA and $5 \mathrm{mmol} \cdot \mathrm{L}^{-1} \mathrm{DMPA}$ at 33 and $10 \mathrm{~Hz}$, respectively. 
Table S4 BCA/MMA PLP experimental conditions and results selected for $k_{\mathrm{p}, \text { cop }}$ estimates with [DMPA] $=5 \mathrm{mmol} \cdot \mathrm{L}^{-1}$ at $4-6 \mathrm{~mJ} / \mathrm{pulse}$. All experiments performed at Queen's University except the values in italics which were performed at the Polymer Institute SAS.

\begin{tabular}{|c|c|c|c|c|c|c|c|c|c|c|c|}
\hline \multirow{4}{*}{$\begin{array}{c}\mathrm{T} \\
\left({ }^{\circ} \mathrm{C}\right)\end{array}$} & \multirow{4}{*}{$\begin{array}{l}\text { Pulse Repetition Rate } \\
\qquad(\mathrm{Hz})\end{array}$} & \multirow{4}{*}{$f_{\mathrm{BCA}}$} & \multirow{4}{*}{$F_{B C A}$} & \multirow{4}{*}{$\begin{array}{c}\text { Conversion } \\
\%\end{array}$} & \multicolumn{7}{|c|}{ SEC Results } \\
\hline & & & & & \multicolumn{3}{|c|}{ RI } & \multicolumn{3}{|c|}{$\mathrm{LS}$} & \multirow{3}{*}{$k_{\mathrm{p}, \mathrm{cop}, \mathrm{LS}} / k_{\mathrm{p}, \mathrm{cop}, \mathrm{RI}}$} \\
\hline & & & & & $\mathrm{M}_{1}$ & \multirow{2}{*}{$\mathrm{M}_{2} / \mathrm{M}_{1}$} & \multirow{2}{*}{$\begin{array}{c}k_{\mathrm{p}, \mathrm{cop}} \text { from } \mathrm{M}_{1} \\
\left(\mathrm{~L} \cdot \mathrm{mol}^{-1} \cdot \mathrm{s}^{-1}\right)\end{array}$} & $\mathrm{M}_{1}$ & \multirow{2}{*}{$\mathrm{M}_{2} / \mathrm{M}_{1}$} & \multirow{2}{*}{$\begin{array}{c}k_{\mathrm{p}, \mathrm{cop}} \text { from } \mathrm{M}_{1} \\
\left(\mathrm{~L} \cdot \mathrm{mol}^{-1} \cdot \mathrm{s}^{-1}\right)\end{array}$} & \\
\hline & & & & & $\left.\begin{array}{c}\left(\mathrm{g} \cdot \mathrm{mol}^{-}\right. \\
1 \\
1\end{array}\right)$ & & & $\left.\begin{array}{c}\left(\mathrm{g} \cdot \mathrm{mol}^{-}\right. \\
1\end{array}\right)$ & & & \\
\hline 30 & 33 & 0 & 0 & 0.3 & 9772 & 2.10 & 346 & 9484 & 2.18 & 336 & 0.97 \\
\hline 30 & 20 & 0 & 0 & 0.3 & 15959 & 2.07 & 343 & - & - & - & - \\
\hline 30 & 33 & 0 & 0 & 0.4 & 11099 & 2.06 & 393 & - & - & - & - \\
\hline 30 & 20 & 0.03 & - & 0.2 & 32592 & 2.12 & 705 & - & - & - & - \\
\hline 30 & 33 & 0.03 & 0.31 & 0.3 & 23384 & 1.94 & 827 & - & - & - & - \\
\hline 30 & 20 & 0.07 & - & 0.3 & 40268 & 1.81 & 868 & - & - & - & - \\
\hline 30 & 33 & 0.07 & - & 0.3 & 23702 & 2.23 & 843 & - & - & - & - \\
\hline 30 & 33 & 0.07 & 0.38 & 0.2 & 27458 & 1.96 & 972 & - & - & - & - \\
\hline 30 & 33 & 0.14 & - & 0.5 & 26031 & 2.05 & 921 & - & - & - & - \\
\hline 30 & 33 & 0.14 & 0.45 & 0.4 & 29481 & 1.97 & 1043 & - & - & - & - \\
\hline 30 & 33 & 0.22 & 0.48 & 0.5 & 30968 & 1.92 & 1096 & - & - & - & - \\
\hline 30 & 33 & 0.50 & 0.54 & 0.5 & 25252 & 1.79 & 894 & - & - & - & - \\
\hline 50 & 50 & 0 & 0 & 0.4 & 12769 & 1.89 & 703 & 14223 & 2.32 & 783 & 1.11 \\
\hline 50 & 33 & 0 & 0 & 1.2 & 19059 & 1.88 & 692 & 18239 & 2.34 & 663 & 0.96 \\
\hline 50 & 50 & 0.03 & 0.30 & 0.4 & 24748 & 2.00 & 1372 & - & - & - & - \\
\hline 50 & 33 & 0.03 & 0.30 & 0.9 & 37137 & 2.01 & 1359 & 29785 & 2.98 & 1090 & 0.80 \\
\hline 50 & 33 & 0.07 & 0.34 & 4.7 & 42936 & 2.00 & 1566 & 47863 & 2.08 & 1746 & 1.11 \\
\hline 50 & 33 & 0.14 & 0.43 & 0.3 & 45738 & 1.98 & 1658 & - & - & - & - \\
\hline 50 & 50 & 0.14 & 0.41 & 0.6 & 32859 & 2.01 & 1805 & - & - & - & - \\
\hline 50 & 33 & 0.14 & 0.45 & 1.0 & 46151 & 2.03 & 1673 & - & - & - & - \\
\hline 50 & 33 & 0.22 & 0.47 & 1.1 & 48149 & 1.88 & 1735 & - & - & - & - \\
\hline 50 & 33 & 0.22 & - & 0.6 & 45686 & 1.99 & 1646 & 53088 & 1.98 & 1912 & 1.16 \\
\hline 50 & 25 & 0.22 & - & 0.2 & 58552 & 2.03 & 1598 & 71779 & 1.88 & 1959 & 1.23 \\
\hline
\end{tabular}




\begin{tabular}{|c|c|c|c|c|c|c|c|c|c|c|c|}
\hline 50 & 50 & 0.22 & - & 1.0 & 32136 & 1.97 & 1754 & 30761 & 2.19 & 1679 & 0.96 \\
\hline 50 & 50 & 0.30 & 0.50 & 2.0 & 31894 & 1.81 & 1730 & 30549 & 1.98 & 1657 & 0.96 \\
\hline 50 & 33 & 0.40 & - & 3.1 & 44872 & 1.97 & 1596 & 47424 & 1.95 & 1687 & 1.06 \\
\hline 50 & 50 & 0.40 & 0.52 & 2.9 & 29509 & 1.93 & 1591 & 31989 & 2.16 & 1724 & 1.08 \\
\hline 50 & 25 & 0.40 & - & 2.8 & 55121 & 2.05 & 1486 & 67143 & 1.90 & 1810 & 1.22 \\
\hline 50 & 33 & 0.50 & 0.55 & 1.8 & 40694 & 1.92 & 1439 & 41591 & 2.00 & 1470 & 1.02 \\
\hline 50 & 50 & 0.50 & 0.56 & 1.5 & 27127 & 2.00 & 1453 & 31769 & 2.08 & 1702 & 1.17 \\
\hline 50 & 25 & 0.50 & - & 1.5 & 49006 & 2.16 & 1313 & 54325 & 2.01 & 1455 & 1.11 \\
\hline 50 & 33 & 0.60 & 0.63 & 1.4 & 36589 & 1.80 & 1285 & 37931 & 1.86 & 1333 & 1.04 \\
\hline 50 & 50 & 0.60 & 0.60 & 0.2 & 25645 & 2.10 & 1365 & - & - & - & - \\
\hline 50 & 50 & 0.72 & - & 0.4 & 17818 & 2.23 & 942 & 23768 & 2.50 & 830 & 0.88 \\
\hline 50 & 50 & 0.72 & - & 0.7 & 22082 & 1.84 & 1168 & - & - & - & - \\
\hline 50 & 20 & 0.85 & 0.68 & 0.3 & 27508 & 2.06 & 578 & - & - & - & - \\
\hline & & & & & & & & & & & \\
\hline 50 & 100 & 0 & - & 1.6 & 6502 & 2.01 & 716 & - & - & - & - \\
\hline 50 & 50 & 0 & - & 1.4 & 12664 & 2.01 & 697 & - & - & - & - \\
\hline 50 & 33 & 0 & - & 3.5 & 19872 & 1.83 & 722 & - & - & - & - \\
\hline 50 & 20 & 0 & - & 3.4 & 30825 & 1.81 & 679 & - & - & - & - \\
\hline 50 & 10 & 0 & - & 3.9 & 55012 & 1.86 & 606 & - & - & - & - \\
\hline 50 & 33 & 0.03 & - & 0.7 & 38128 & 1.79 & 1395 & - & - & - & - \\
\hline 50 & 50 & 0.03 & - & 0.3 & 26664 & 1.80 & 1508 & - & - & - & - \\
\hline 50 & 50 & 0.03 & - & 0.2 & 26788 & 1.79 & 1500 & - & - & - & - \\
\hline 50 & 50 & 0.03 & - & 1.8 & 26912 & 1.78 & 1478 & - & - & - & - \\
\hline 50 & 50 & 0.03 & - & 0.8 & 26974 & 1.78 & 1488 & - & - & - & - \\
\hline 50 & 50 & 0.5 & - & 0.8 & 29214 & 1.85 & 1565 & - & - & - & - \\
\hline 50 & 33 & 0.5 & - & 2.3 & 42107 & 2.03 & 1489 & - & - & - & - \\
\hline 50 & 50 & 0.6 & - & 0.6 & 26929 & 1.82 & 1433 & - & - & - & - \\
\hline 50 & 33 & 0.6 & - & 2.3 & 37583 & 1.99 & 1320 & - & - & - & - \\
\hline 50 & 33 & 0.72 & & 1.6 & 33397 & 1.93 & 1166 & - & - & - & - \\
\hline & & & & & & & & & & & \\
\hline 70 & 33 & 0.00 & 0 & 0.6 & 28599 & 1.98 & 1009 & - & - & - & - \\
\hline 70 & 33 & 0.03 & 0.28 & 1.2 & 53429 & 2.15 & 1884 & - & - & - & - \\
\hline
\end{tabular}




\begin{tabular}{|l|l|l|l|l|l|l|l|l|l|l|l|}
\hline 70 & 33 & 0.07 & - & 1 & 62421 & 2.19 & 2201 & - & - & - & - \\
\hline 70 & 33 & 0.14 & - & 2.7 & 68153 & 2.23 & 2403 & - & - & - \\
\hline 70 & 33 & 0.22 & - & 1.2 & 68065 & 2.24 & 2400 & - & - & - \\
\hline
\end{tabular}




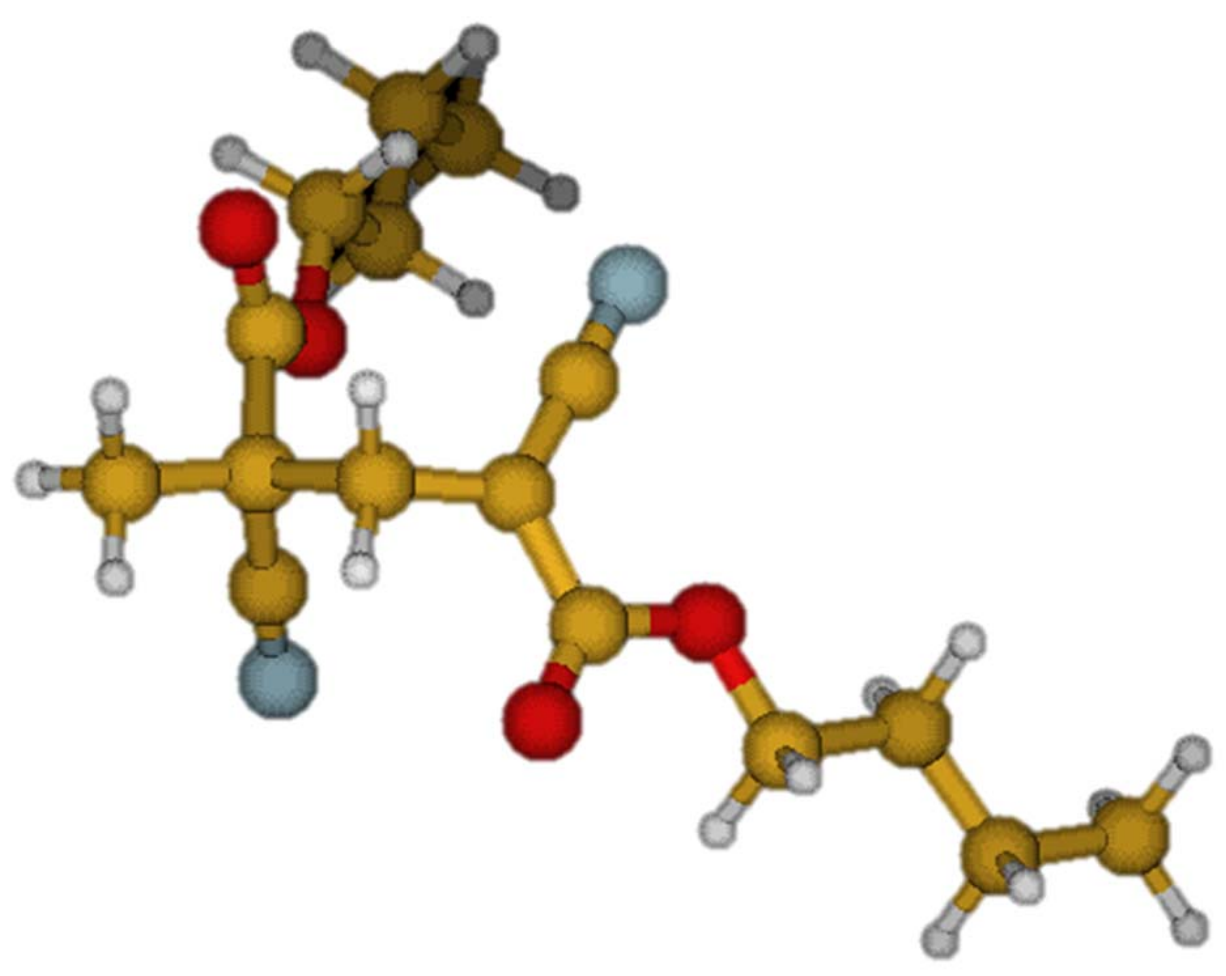

Figure S5: Minimum energy BCA dimer radical structure according to QM calculations 
Atom coordinate details for the optimized transition state structures corresponding to the investigated propagation reactions.

\begin{tabular}{|c|c|c|c|}
\hline \multicolumn{4}{|c|}{$\mathrm{BCA}^{*}+$ BCA $\rightarrow$ BCA_BCA* } \\
\hline $\mathrm{C}$ & & & \\
\hline $\mathrm{C}$ & & & \\
\hline f & & & \\
\hline$\checkmark$ & 5436 & 349 & \\
\hline & & & \\
\hline$C$ & & & \\
\hline $\mathrm{C}$ & & & \\
\hline $\mathrm{N}$ & 98 & & \\
\hline & & & \\
\hline $\mathrm{O}$ & & & \\
\hline $\mathrm{C}$ & & & \\
\hline 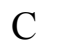 & & & \\
\hline & & & \\
\hline & & & \\
\hline 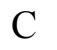 & & & \\
\hline $\mathrm{C}$ & & & \\
\hline U & & & \\
\hline 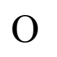 & & & \\
\hline $\mathrm{H}$ & & & \\
\hline $\mathrm{H}$ & & & \\
\hline $\mathrm{H}$ & & & \\
\hline $\mathrm{H}$ & & & \\
\hline $\mathrm{H}$ & & & \\
\hline $\mathrm{H}$ & & & \\
\hline $\mathrm{H}$ & & & \\
\hline & & & \\
\hline $\mathrm{H}$ & & & \\
\hline $\mathrm{H}$ & & & \\
\hline $\mathrm{H}$ & -3 . & & \\
\hline & & & \\
\hline $\mathrm{C}$ & & & \\
\hline $\mathrm{H}$ & & & \\
\hline $\mathrm{H}$ & & & \\
\hline $\mathrm{C}$ & & & \\
\hline $\mathrm{H}$ & & & \\
\hline $\mathrm{H}$ & & & \\
\hline $\mathrm{H}$ & -2.8 & & \\
\hline $\mathrm{H}$ & & & \\
\hline . & & & \\
\hline $\mathrm{C}$ & & & \\
\hline $\mathrm{H}$ & & 024 & \\
\hline & & & \\
\hline & & & \\
\hline $\mathrm{H}$ & & & \\
\hline 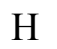 & 6.515038 & 2.414874 & 0.482 \\
\hline
\end{tabular}




$\begin{array}{crrr}\text { BCA + MMA } & \rightarrow \text { BCA MMA* } \\ \text { C } & 4.179300 & -0.435536 & -0.250311 \\ \text { C } & 3.199718 & 0.724266 & -0.313767 \\ \text { O } & 1.978068 & 0.303823 & 0.341345 \\ \text { C } & 0.984050 & 1.214338 & 0.377890 \\ \text { O } & 1.048380 & 2.321513 & -0.120156 \\ \text { C } & -0.237943 & 0.690849 & 1.054322 \\ \text { C } & -1.315487 & 1.703933 & 1.353150 \\ \text { C } & -0.974263 & -0.421573 & -0.716025 \\ \text { C } & -2.224530 & -0.944849 & -0.445928 \\ \mathrm{C} & -2.431569 & -2.275842 & 0.213011 \\ \mathrm{C} & -0.068190 & -0.376618 & 1.983788 \\ \text { N } & 0.013851 & -1.262357 & 2.738999 \\ \mathrm{C} & -3.394897 & -0.101812 & -0.796029 \\ \mathrm{O} & -4.565412 & -0.731663 & -0.540318 \\ \mathrm{C} & -5.747718 & 0.016718 & -0.865712 \\ \mathrm{O} & -3.333265 & 1.022937 & -1.264548 \\ \mathrm{H} & -0.913776 & 0.465557 & -1.337577 \\ \mathrm{H} & -0.107932 & -1.073167 & -0.689101 \\ \mathrm{H} & 3.583248 & 1.613788 & 0.196792 \\ \mathrm{H} & 2.966044 & 1.011520 & -1.344501 \\ \mathrm{C} & 5.519268 & -0.099133 & -0.917741 \\ \mathrm{H} & 4.340712 & -0.708305 & 0.799654 \\ \mathrm{H} & 3.728997 & -1.310634 & -0.735431 \\ \mathrm{H} & -2.963029 & -2.167982 & 1.165652 \\ \mathrm{H} & -3.052437 & -2.927853 & -0.411953 \\ \mathrm{H} & -1.478882 & -2.770511 & 0.409340 \\ \mathrm{H} & -5.765844 & 0.263711 & -1.929997 \\ \mathrm{H} & -6.585386 & -0.630286 & -0.606998 \\ \mathrm{H} & -5.785942 & 0.944627 & -0.289831 \\ \mathrm{H} & -0.973820 & 2.392935 & 2.135408 \\ \mathrm{H} & -1.541598 & 2.289018 & 0.461210 \\ \mathrm{H} & -2.224778 & 1.213790 & 1.705279 \\ \mathrm{C} & 6.517165 & -1.259409 & -0.860027 \\ \mathrm{H} & 5.345777 & 0.182782 & -1.964861 \\ \mathrm{H} & 5.956909 & 0.783884 & -0.433251 \\ \mathrm{H} & 7.464657 & -0.992128 & -1.338001 \\ \mathrm{H} & 6.734035 & -1.543513 & 0.175552 \\ \mathrm{H} & 6.124482 & -2.145597 & -1.370687\end{array}$




\begin{tabular}{|c|c|c|c|}
\hline \multicolumn{4}{|c|}{$\mathrm{MMA}^{*}+$ BCA $\rightarrow$ MMA_BC } \\
\hline $\mathrm{C}$ & נטנ & J & \\
\hline & & & \\
\hline & & & \\
\hline $\mathrm{C}$ & & & \\
\hline $\mathrm{O}$ & & & \\
\hline & & & \\
\hline & & & \\
\hline $\mathrm{N}$ & & & \\
\hline $\mathrm{C}$ & & & \\
\hline & & & \\
\hline $\mathrm{C}$ & & & \\
\hline 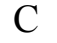 & & & \\
\hline 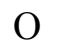 & & & \\
\hline & & & \\
\hline $\mathrm{C}$ & & & \\
\hline $\mathrm{O}$ & & & \\
\hline$\Pi$ & & & \\
\hline $\mathrm{H}$ & -1. & & \\
\hline $\mathrm{H}$ & & & \\
\hline $\mathrm{H}$ & & & \\
\hline 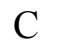 & & & \\
\hline $\mathrm{H}$ & & & \\
\hline $\mathrm{H}$ & & & \\
\hline $\mathrm{H}$ & & & \\
\hline $\mathrm{H}$ & -2.3 & & \\
\hline $\mathrm{H}$ & & & \\
\hline $\mathrm{H}$ & -3.5 & & \\
\hline $\mathrm{H}$ & & & \\
\hline $\mathrm{H}$ & -2.6 & & \\
\hline U & & & \\
\hline 11 & -3.2 & -2.5 & \\
\hline $\mathrm{H}$ & -4.5 & & \\
\hline $\mathrm{C}$ & & & \\
\hline & & & \\
\hline 11 & & -0.9 & \\
\hline $\mathrm{H}$ & & & \\
\hline $\mathrm{H}$ & & 063 & -0.2 \\
\hline & 6.266330 & 1.662181 & 1.403 \\
\hline
\end{tabular}




\begin{tabular}{|c|c|c|c|}
\hline \multicolumn{4}{|c|}{ MMA*+MMA $\rightarrow$ MMA_MMA* } \\
\hline $\mathrm{C}$ & 0.997874 & $-0.2219 \overline{73}$ & -0.9502 \\
\hline $\mathrm{C}$ & 0.088614 & 0.736752 & \\
\hline $\mathrm{C}$ & -1.450037 & & \\
\hline $\mathrm{H}$ & 389 & 503 & 5572 \\
\hline $\mathrm{H}$ & -0.705322 & 56 & \\
\hline $\mathrm{C}$ & -2.069213 & & \\
\hline $\mathrm{H}$ & -2.865126 & 2.7 & \\
\hline $\mathrm{H}$ & -1.3 & & \\
\hline $\mathrm{H}$ & -2.5 & & \\
\hline $\mathrm{C}$ & -0.6 & & \\
\hline $\mathrm{H}$ & & & \\
\hline $\mathrm{H}$ & -1.27 & & \\
\hline $\mathrm{H}$ & -0.1 & & \\
\hline $\mathrm{C}$ & & & \\
\hline $\mathrm{H}$ & -0.1 & & \\
\hline $\mathrm{H}$ & 1.6 & -2.1 & -1 . \\
\hline $\mathrm{H}$ & 0.7 & -2.2 & \\
\hline $\mathrm{C}$ & 2.2 & & \\
\hline $\mathrm{O}$ & & & \\
\hline $\mathrm{O}$ & 3.0 & -0.7 & \\
\hline $\mathrm{C}$ & 4.24 & -0.4 & \\
\hline $\mathrm{H}$ & 4.8 & -1.3 & \\
\hline $\mathrm{H}$ & 4.8 & 0.3 & 0.1 \\
\hline $\mathrm{H}$ & 4.016 & 0.0 & 1.7 \\
\hline $\mathrm{C}$ & -2.22 & -0.0 & 0. \\
\hline $\mathrm{O}$ & -3.0 & -0.2 & -0 . \\
\hline $\mathrm{O}$ & -1.8 & -1.0 & 0.9 \\
\hline $\mathrm{C}$ & -2.576174 & -2.329348 & 0.73830 \\
\hline $\mathrm{H}$ & -2.40 & -2.7 & -0.2 \\
\hline $\mathrm{H}$ & -2.188655 & -3.005799 & \\
\hline $\mathrm{H}$ & -3.649544 & -2.174582 & 0.8730 \\
\hline
\end{tabular}




\section{Pulsed-laser and Quantum Mechanics Study of $\boldsymbol{n}$-Butyl Cyanoacrylate and Methyl Methacrylate Free-Radical Copolymerization}

Thomas R. Rooney, Evangelos Mavroudakis, Igor Lacík, Robin A. Hutchinson,* Davide Moscatelli*

Polym. Chem. 2014, submitted ( )

This manuscript describes the application of the pulsed-laser polymerization (PLP) technique to investigate radical (co)polymerization propagation kinetics of methyl methacrylate with butyl cyanoacrylate (BCA), as cyanoacrylate copolymers show promise as a potential material to produce nanoparticles for drug delivery. As always, careful establishment of proper calibrations for size-exclusion chromatographic analysis of polymer molar mass distribution is a key part of the effort, and the experimental results are corroborated by a computational chemistry investigation by the group of Moscatelli.

The work is significant in two regards. The new results help us interpret how monomer and radical structure influence reactivity by comparing BCA kinetics to butyl methacrylate and butyl acrylate, and also demonstrated the usefulness of computational techniques to estimate relative rate coefficients such as copolymerization reactivity ratios. Secondly, the study demonstrates the the ability to copolymerize highly reactive cyanoacrylates through radical polymerization, enabling a greater control over polymer MW characteristics and degradative behavior while providing a means to tailor polymer properties otherwise inaccessible by anionic polymerization.

The work is an example of the approach that my group will continue to follow as we collaboratively study with Moscatelli the use of radical polymerization to produce biodegradable nanoparticles with controlled size and degradation rates: it is only through the fundamental understanding of polymerization kinetics that we gain the knowledge required to tailor synthesis conditions to manipulate polymer microstructure and functionality. 


\section{Pulsed-laser and Quantum Mechanics Study of $\boldsymbol{n}$-Butyl Cyanoacrylate and Methyl Methacrylate Free-Radical Copolymerization}

Thomas R. Rooney, Evangelos Mavroudakis, Igor Lacík, Robin A. Hutchinson,* Davide Moscatelli*

Polym. Chem. 2014, submitted ( )

Radical copolymerization of butyl cyanoacrylate and methyl methacrylate leads to an alternating copolymer which is stabilized against degradation, illustrating that an otherwise inaccessible (via anionic polymerization) level of control can be achieved to improve potential drug delivery applications.

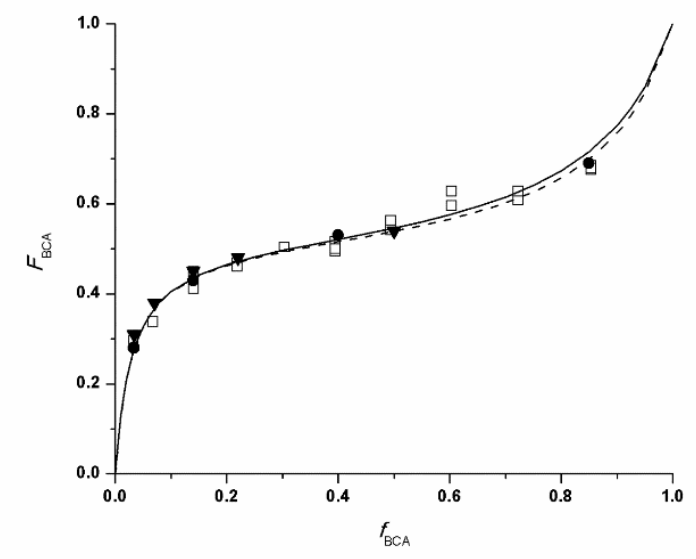

